Discussion

Papers

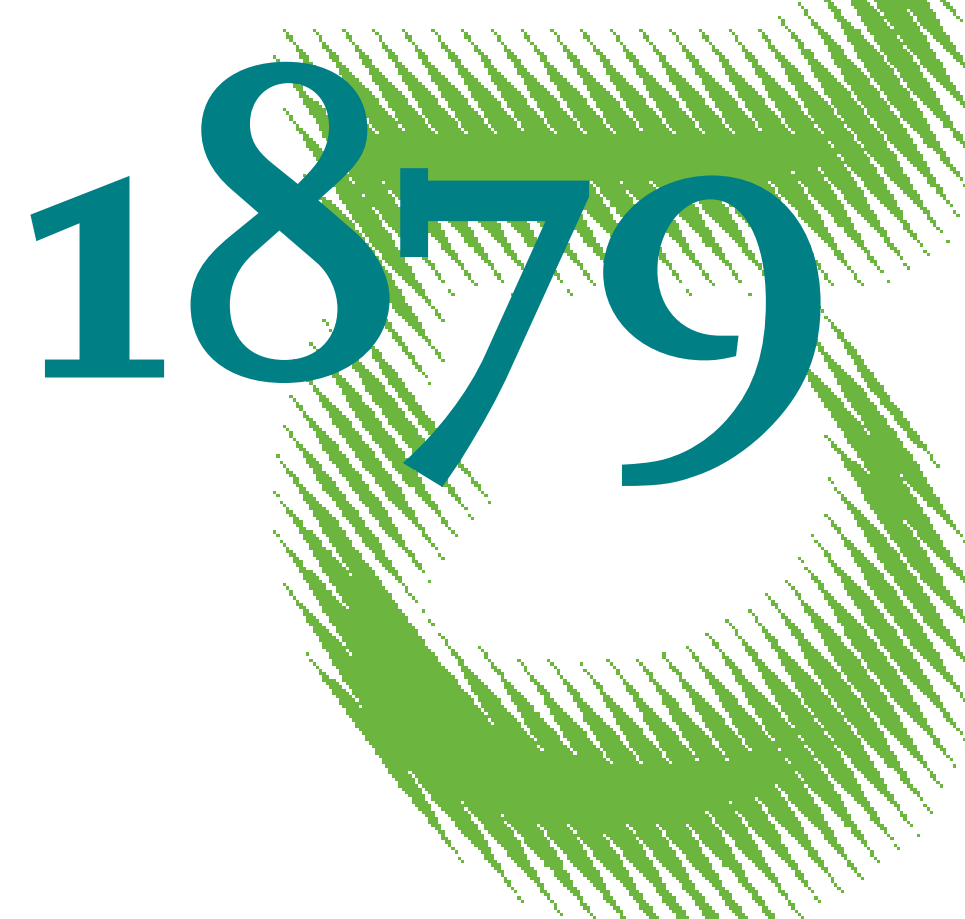

allil

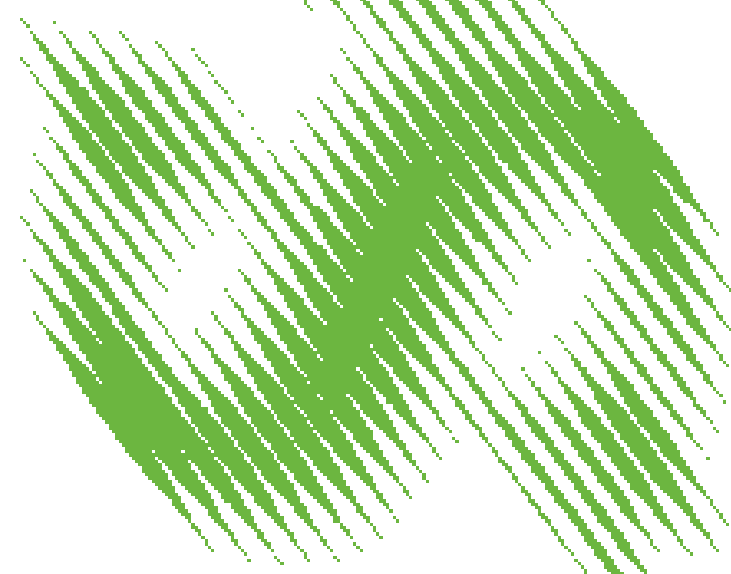

311111111111111

I Am Innocent: Hourly Variations in Air Pollution and Crime Behavior 
Opinions expressed in this paper are those of the author(s) and do not necessarily reflect views of the institute.

IMPRESSUM

(C) DIW Berlin, 2020

DIW Berlin

German Institute for Economic Research

Mohrenstr. 58

10117 Berlin

Tel. +49 (30) $89789-0$

Fax +49 (30) $89789-200$

http://www.diw.de

ISSN electronic edition 1619-4535

Papers can be downloaded free of charge from the DIW Berlin website:

http://www.diw.de/discussionpapers

Discussion Papers of DIW Berlin are indexed in RePEc and SSRN:

http://ideas.repec.org/s/diw/diwwpp.html

http://www.ssrn.com/link/DIW-Berlin-German-Inst-Econ-Res.html 


\title{
I am Innocent: Hourly Variations in Air Pollution and Crime Behavior
}

\author{
Luis Sarmiento*
}

June 26, 2020

\begin{abstract}
I posit that hourly changes in air pollution affect criminality through two distinct pathways, via physiological effects on the criminal and by changes in the tightness of the market for criminal activities. To disentangle individual from market effects, I develop a behavioral model of the individual decision to transgress and a model of search-and-matching frictions between criminals and crime opportunities. The study examines the impact on the four largest cities in North America. Causality emerges from instrumental variable panel-models. Results show that pollution increases violent and unpremeditated crimes while decreasing burglaries and sexual offenses through a reduction of crime opportunities.
\end{abstract}

JEL codes: K14; Q53, I18; H23;

Keywords: Local air pollution, criminality, external effects, prospect theory, search and matching frictions, panel models. 


\section{Introduction}

Local air pollution in urban centers is a negative local externality driven by the continuous emission of chemical compounds to the atmosphere. Basic economic theory teaches us that the optimum level of air contaminants should happen at the point of intersection between the adverse effects of exposure and the positive benefits from economic output (Pareto and Cours, 1896; Kaldor, 1939). For example, if the pollution-related costs of economic activity surpass its benefits, a rational social planner should opt for reducing anthropogenic emissions. However, there are still unknowns concerning both the costs and benefits of air pollution. This article aims to contribute to the literature on the effects of air pollution on society by analyzing how hourly variations in the measurements of criteria pollutants affect crime across the four largest urban agglomerations in North America: Mexico City, Los Angeles, Toronto, and New York City.

The study contributes to the literature in several ways. First, it is the first article providing a theoretical intuition for both mechanisms behind the relationship of air pollution and crime: the individual maximization of utility by the criminal, as well as the matching between felons and crime opportunities. Second, it is the first to model the criminal's maximization of utility by incorporating irrational behavior and different risk perceptions with the use of cumulative prospect theory. Third, it is the first to present a model of search and matching frictions to illustrate how air pollution does affect not only the personal decision to commit a crime but also the tightness of the market for criminal activities 11 On the empirical side, it is the first study estimating the hourly effect of exposure to air pollution on criminality, the first to evaluate the impact for all measured criteria contaminants, and the first to identify an adverse effect of pollution on crime categories more dependant on the ratio of criminals and crime opportunities in the market.

In principle, the relationship between crime and air pollution could go in either direction. Heightened concentrations can cut felonies down by reducing the number of victims and active criminals through intensified morbidity. At the same time, they can also increase crime by changing the physiological, environmental, and psychological circumstances of the felon (Herrnstadt and Muehlegger, 2015; Herrnstadt et al., 2016; Bondy et al., 2020, Burkhardt et al. 2019). I try to explore and identify both effects by examining different effects of exposure across different crime categories and by using the models of search-and-matching frictions

\footnotetext{
${ }^{1}$ The tightness of the market is the ratio between crime opportunities and active criminals.
} 
and prospect theory to provide an economic intuition for both outcomes. In a nutshell, the model on the individual decision to commit a crime proposes that air pollution can affect the criminal's decision through four variables, the shape of the utility function, the probability of apprehension, the criminal's weighting of this probability, and the discounting of future punishments. Concerning the model on search-and-matching frictions, it proposes that higher levels of air pollution can reduce the number of available crime opportunities through exacerbated morbidity or avoidance behavior. The results of this study can be used by the police to shift surveillance resources between crimes, policymakers in cost-benefit analysis of environmental policies, and epidemiologists as evidence for a neural connection between specific contaminants and subversive behavior.

To analyze the short term effect of air pollution on criminality, I merge administrative crime data for each urban center with hourly pollution measurements. The pollution data contain information on six different criteria pollutants; carbon monoxide $(\mathrm{CO})$, nitrogen dioxide $\left(\mathrm{NO}_{2}\right)$, ozone $\left(\mathrm{O}_{3}\right)$, coarse particle matter $\left(P M_{10}\right)$, fine particle matter $\left(P M_{25}\right)$, and sulfur dioxide $\left(\mathrm{SO}_{2}\right)$. For each crime category, I count the number of events occurring in a two-kilometer radius around each monitoring station and infer causality from the use of panel techniques that exploit the temporal and spatial heterogeneity of exposure values across measuring stations. Specifically, I control for weather covariates like temperature and relative humidity plus hour, weekday, month, year, and station fixed effects. Moreover, the preferred specification uses wind direction as an instrument to avoid the possibility of time-varying unobservables contaminating the results.

The goal of the empirical model is to infer if, in hours with high levels of environmental pollution, the crime rates within a two-kilometer radius around the measuring stations vary in any significant way. In the preferred specification, I find that increasing the hourly concentration of $\mathrm{O}_{3}, \mathrm{NO}_{2}$, and $\mathrm{PM}_{25}$ by one standard deviation increases criminality by $11.37 \%, 5.57 \%$, and $6.79 \%$, respectively. Also, I show that a significant portion of this positive and consistently significant effect accrues to violent felonies. Increasing the level of $\mathrm{CO}, \mathrm{NO}_{2}, \mathrm{PM}_{25}$, $P M_{10}$, and $O_{3}$ by one standard deviation increases violent felonies by $4.38 \%, 5.03 \%, 6.13 \%$, $4.53 \%$, and $8.12 \%$, respectively. Additionally, I dig into the impact of pollution on violent crimes to understand if the effect comes from the brutality of the offense or the unpremeditated nature of most violent transgressions. To disentangle both effects, I compare two commonly unpremeditated confrontational offenses (aggravated and non-aggravated assaults) and two un- 
premeditated property crimes (robbery and larceny). The crimes within each category only vary in their level of exercised violence, while remaining very similar in the ultimate goal of the criminal. Thus, higher point estimates for the more violent felonies (aggravated assault and robbery) suggest that the brutal nature of the crimes drive the coefficients. The results from this exercise show higher point estimates for aggravated assaults and robbery, suggesting that it is indeed an exacerbated taste for violence behind the increments in violent felonies.

Analyzing each crime category, I find that although several crimes increase because of higher levels of pollution, some, more dependent on the matching of criminals and crime opportunities, decrease. For example, the regression results point to a decrease in burglaries when the levels of $\mathrm{CO}, \mathrm{NO}_{2}, \mathrm{PM}_{25}$, and $\mathrm{O}_{3}$ increase. I explain this opposite effect with the search and matching frictions model of criminals and crime opportunities and by referring to the extensive literature on the negative impact of air pollution on labor supply, school attendance, and the propensity to participate in outside activities during periods of high pollution (Hanna and Oliva, 2015; Currie et al., 2009; Zivin and Neidell, 2009). If persons miss work, school, or tend to remain indoors when pollution is high, the number of empty houses to burgle decreases. These last results show an outcome previously disregarded by the literature on the relationship between crime and pollution, the effect of pollution on the matching between crime opportunities and criminals. Furthermore, the result also uncovers the possibility that for those felonies with positive coefficients, we may be finding lower-bound estimates.

Concerning different effects across locations, I find that although crimes increase in outside, commercial, and residential premises, the impact is consistently higher for outside premises (the street). Regarding the inter-temporal behavior of crime after exposure, I find that there is a large degree of temporal substitution between the contemporaneous and lead impacts, meaning that the effects at time $t+k$ partially compensate the consequences at time $t$. However, even after this compensation, the cumulative impact for twelve and twenty-four hours after exposure remains positive and significant for violent offenses. The empirical section concludes with a non-linear analysis of the relationship between air pollution and crime. In this analysis, I provide evidence for a linear relationship between $P M_{25}$ and violent offenses like assault and robbery, also a linear relationship also with non-violent unpremeditated crimes like larceny, and an inverted u-shape relation for two crime categories, sexual crimes, and burglary.

Using the empirical results alongside the models on search and matching frictions and prospect theory, I propose plausible mechanisms for the effect of air pollution on crime. First, 
I suggest that crimes increase because of a rise in the taste for violent behavior. Second, even though the majority of non-violent offenses appear insignificant, there is a selected group of non-violent felonies that spur significance, in particular, unpremeditated non-violent crimes like larceny. I propose that pollution affects the propensity of larceny either by changing the individual weighting of real-world apprehension-probabilities or by changing the discounting of future punishments. Finally, for some crimes like burglary, the reduction in the match between criminals and crime opportunities drive their opposite effect.

\section{Literature Review}

Existing studies on the costs of air pollution on the society show evidence of a negative impact on different aspects of personal well-being like health (Moretti and Neidell, 2011; Barwick et al., 2018), mortality (Jayachandran, 2009; Knittel et al., 2016), labor supply (Hanna and Oliva, 2015; Aragon et al., 2016), labor productivity (Zivin and Neidell, 2012; Chang et al., 2019), human capital formation (Currie et al., 2009; Chen et al., 2018), and, most relevant for this study, criminality (Burkhardt et al., 2019; Bondy et al., 2020; Herrnstadt et al., 2016, Herrnstadt and Muehlegger, 2015).

The relationship between pollution and criminality emerges from physiological, psychological, or environmental causes. Physiological causes relate to the effect of air particles on the body; for instance, air pollutants affect our minds by promoting an inflammatory response on the nervous tissue (Beurel and Jope, 2014) or by using the blood-stream to reach the central nervous system, directly interfering with its chemical composition (Block and CalderónGarcidueñas, 2009). Altering the brain's chemistry can lead to behavioral changes like irritability, changes in risk preferences, or eagerness for rewards. For example, there is epidemiological evidence that higher concentrations of ozone can increase aggressive, impulsive, and overexcited behavior in animals (Chen et al., 2003, Petruzzi et al., 1995; Soulage et al., 2004), changes on risk attitudes in human beings (Heyes et al., 2016; Bondy et al., 2020), and affectations in the brain's level of serotonin (Murphy et al. 2013); a chemical compound that works as an inhibitor of impulsive and aggressive behaviors. Crockett et al. (2013) find that lower levels of serotonin can lead to an eagerness to punish enemies and a lower tendency for accepting fair deals. Regarding psychological reasons, there is evidence that air pollution can cause discomfort through exacerbated morbidity, and that, in turn, discomfort can cause aggressive behavior 
in humans (Anderson and Bushman, 2002). Furthermore, empirical analyses of the effect of air pollution on other proxies for criminal behavior find associations with family disturbances (Rotton and Frey, 1985), psychiatric admissions (Briere et al., 1983), and suicides (Yang et al. 2011).

Concerning environmental effects, exposure to urban air pollution can decrease the number of potential victims, active criminals, and police units by forcing them to stay at home or visit the hospital. For instance, Iskandar et al. (2012) shows that air pollution increases hospitalization rates, Tolbert et al. (2000) presents evidence of increased pediatric emergency room visits, and Knittel et al. (2016) concludes that air pollution rises mortality. Moreover, proof of the effect of pollution triggered morbidity on the number of persons in the street comes from articles analyzing the impact of exposure on other proxies for individual behavior. For example, Aragon et al. (2016) and Hanna and Oliva (2015) find that higher concentrations of sulfur dioxide and coarse particle matter decrease labor supply, Gilliland et al. (2001) and Currie et al. (2009) that high levels of air contaminants increase school absenteeism, and Zivin and Neidell (2009) that avoidance behavior increases in periods of high levels of exposure to air contaminants.

To the best of my knowledge, four other articles look at the connection between air pollution and criminal behavior: Burkhardt et al. (2019), Bondy et al. (2020), Herrnstadt et al. (2016), and Herrnstadt and Muehlegger (2015). All explore the effect of daily variations in air pollution on criminality. Herrnstadt and Muehlegger (2015) analyze the effect of air pollution on daily variations of illegal activities in Chicago. Using wind patterns as an instrument, they infer that violent crime increases by $2.2 \%$ in areas downwind of a known pollution source, interstate highways. Additionally, they suggest that because of the high correlation between nitrous oxides and summer-traffic, variation in this contaminant might be behind such effect. Herrnstadt et al. (2016) examine the impact of ozone on the crime rates of Los Angeles. The authors find by using wind direction in a fixed-effects instrumental variable (IV) regression design that increasing ozone exposure by ten particles per billion, raise the number of aggravated assaults by $4 \%$ in the vicinity of measuring stations. Bondy et al. (2020) use daily administrative data from London, alongside fixed effects instrumental variable techniques to conclude that increasing the air quality index in London has positive and significant consequences for overall crime, particularly for less severe offenses. Increasing the air quality index by ten units increases crimes by $1.7 \%$. Finally, Burkhardt et al. (2019) uses American crime statistics as 
well as daily data on ozone and fine particle matter to conclude that for 397 counties, increasing particle matter and ozone by ten percent rises violent crimes by $0.14 \%$ and $0.35 \%$, respectively.

This article contributes to current literature on the relationship between air pollution and criminality in several ways. First, it is the first article analyzing the effect of hourly variations in exposure, allowing me to control for all of those correlated covariates with temporal variation at the hourly, daily, monthly, and yearly levels. Additionally, studying the hourly effect uncovers a more immediate impact of exposure, which is less likely to be contaminated by unobservables. Second, this article analyzes the connection between crime rates and all measured criteria pollutants. This global analysis differentiates from the majority of studies on the external effects of pollution by showing the impact across all particles and analyzing the possible reasons for significance and point estimate variation between them. Given the high complexity of environmental pollution, it is better to concentrate on all measured particles, as by reason of the substantial correlation between them, claiming causality for only one may shadow the effects of other compounds or avoid discussing unexpected and counter-intuitive results for other. For example, internal combustion vehicles are the primary source of carbon monoxide, nitrogen oxides, and particle matter in urban environments, examining only one of these particles and claiming an impact is very likely to shadow the effect of other correlated contaminants. Furthermore, it is also essential to study the effect of each particle instead of constructing pollution indexes as some pollutants are negatively correlated and could shadow each other's effect. For instance, ozone and traffic contaminants have opposite seasonal patterns because of the effect of nitrogen oxides on the creation and destruction of ozone, in cities with high levels of both traffic contaminants and ozone, the reduction in one of them could shadow the negative impact of the other. Third, this paper analyses the consequences of exposure on the four biggest urban centers in North America; Los Angeles, Mexico City, New York, and Toronto. These cities are in three different countries and span across very different climates, cultures, and levels of air contaminants. Between them, they encompass around twenty-four million inhabitants within city limits and more than sixty million residents in their metropolitan areas. Fourth, I build on Bondy et al. (2020) by expanding its expected utility theoretical background of the connection between air pollution and criminality with prospect theory. Fifth, I include an additional theoretical explanation for the relationship between pollution and crime rates by describing a framework with search and matching frictions between criminals and crime opportunities. Sixth, I provide the first evidence that air pollution affects 
not only the individual decision to commit a crime but also the balance between criminals and crime opportunities in the market. As such, I show that for burglary and sexual crimes, the number of crimes decreases with pollution.

\section{Theoretical background}

\subsection{The individual's decision to commit a crime}

Under expected utility theory, a person refrains from criminal activities, if the utility from criminality is lower than the utility from restraint (Becker, 1968). This condition is often called the "no crime condition". Equation 1 portrays the functional form behind this condition. In it, $p$ is the probability of arrest, $y_{c}$ the income from the felony, $F$ is the cost of punishment, $\beta$ the discounting rate of future penalties, and $y_{n c}$ is the income from not committing the offense.

$$
p U\left(y_{c}-\beta F\right)+(1-p) U\left(y_{c}\right) \geq U\left(y_{n c}\right)
$$

In their article analyzing the effect of air pollution on crime, Bondy et al. (2020) use this theoretical framework to explain how air pollution could affect the individual probability of committing a crime; they point out that exposure can change the criminal's decision through its effect on expected income streams, risk perceptions, or risk preferences. For example, air pollution could reduce the probability of detection because of visibility constraints, change the perception of payoffs through the discounting of future punishments, or modify the risk behavior of individuals to more risk-averse or risk-seeking forms. In this article, I build upon Bondy et al. (2020) by incorporating irrational behavior and different risk perceptions with the use of cumulative prospect theory (Tversky and Kahneman, 1992).

Imagine a lottery in the form $\mathscr{L}=\left(x_{-m}, \ldots, x_{0}, \ldots, x_{n} ; p_{-m}, \ldots, p_{0}, \ldots, p_{n}\right)$, where $x_{-m}>$ $x_{0}>x_{n}$ are outcomes and $p_{\gamma}$ for $\gamma \in c(-m, \ldots, 0, \ldots, n)$ probabilities of each outcome. In cumulative prospect theory, criminals elicit their utility from a reference point $\left(y_{0}\right)$. The reference point determines the functional shape of their utility function, and, thus, their risk behavior varies depending on the relationship between outcomes and the reference point. If the outcome is larger than the reference point, the individual is in the gains section, and when it is smaller, in the losses section. The use of a reference point allows specifying a functional form that can incorporate descriptive evidence on different risk perceptions stemming from the literature on behavioral economics (Olsen, 1997). 
On the gains side, the utility function is concave, signaling decreasing returns to higherincome; wining one extra hundred dollars on a bank heist of several millions does not have a significant effect in the experienced utility of the thief. On the losses side, the utility function is convex, showing increasing costs of higher losses; if arrested, the utility loss grows disproportionally with each extra year of prison. Equation 2 shows the standard functional form of the utility function under prospect theory (Tversky and Kahneman, 1992):

$$
U(x)=\left\{\begin{array}{l}
x^{\gamma} \leftrightarrow x \geq 0 . \\
-\theta(-x)^{\rho} \leftrightarrow x<0 .
\end{array}\right.
$$

In this equation, $x$ represents the income value concerning the reference point $(x=y-$ $y_{0}$ ). The parameters $\rho$ and $\gamma$ specify the form of the utility function across each threshold and $\theta$ is a parameter modifying the individual's aversion to risk. All three parameters, $\theta, \gamma$, and $\rho$ lie between zero and one. As a simplifying assumption, a person is in the domain of gains when not caught and of losses when arrested. If discovered, the payoff is equivalent to $x_{c}=y_{c}-\beta F-y_{0}<0$; if not, $x_{c}=y_{c}-y_{0} \geq 0$ Moreover, there is evidence that persons do not rationally internalize probabilities in the real world. On average, people underestimate probabilities close to one and overestimate probabilities close to zero (Kahneman and Tversky, 1979). To weight the probability of being caught, I use the prelec weighting function (Prelec et al., 1998). The functional form of the prelec function is $w_{i}(p)=\exp \left\{-B[-\ln (p)]^{\alpha}\right\}$, where $\alpha$ and $B$ are two constants determining the shape of the function, while $p$ is the probability of being caught. Figure 2 portrays the form of both the utility function under prospect theory and the prelec weighting function.

If we substitute into the "no crime condition" of expected utility theory the prelec weighting function and the different risk profile across gains and losses of behavioral prospect theory, equation 1 becomes equation 3 .

$$
w(p) u\left[\left(y_{c}-\beta F\right)-y_{0}\right]+w(1-p) u\left(y_{c}-y_{0}\right)>u\left(y_{n c}-y_{0}\right)
$$

In it, $y_{0}$ is the reference point from where the criminal elicits its risk behavior, $y_{c}$ is the income from committing the criminal offence, and $y_{n c}$ the income from restraining. Additionally, substituting Tversky and Kahneman (1992) utility function into equation 3, we get the "no crime

\footnotetext{
${ }^{2} \mathrm{~A}$ utility function under cumulative prospect theory satisfies three important conditions: Zero utility: $U(0)=0$, concavity in gains: if $x_{i} \geq 0 \longrightarrow U^{\prime}(x)>0 \wedge U^{\prime \prime}(x)<0$, and convexity in losses if $x_{i}<0 \longrightarrow U^{\prime}(x)>$ $0 \wedge U^{\prime \prime}(x)>0$.
} 


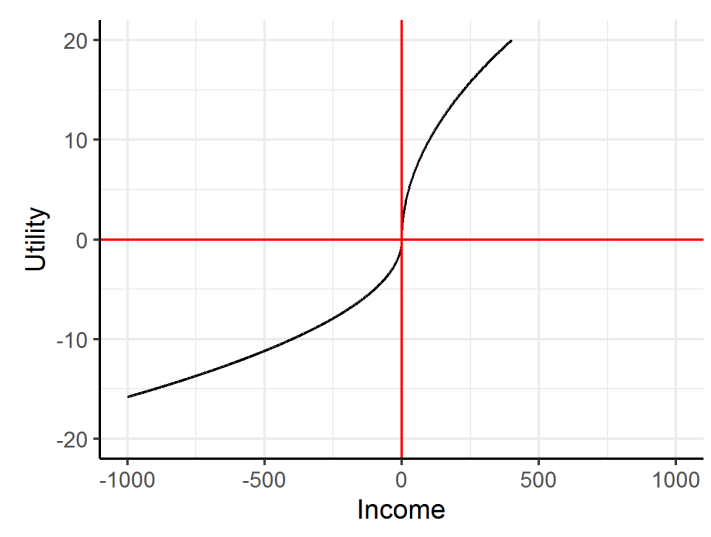

(a) Tversky and Kahneman (1992) utility function

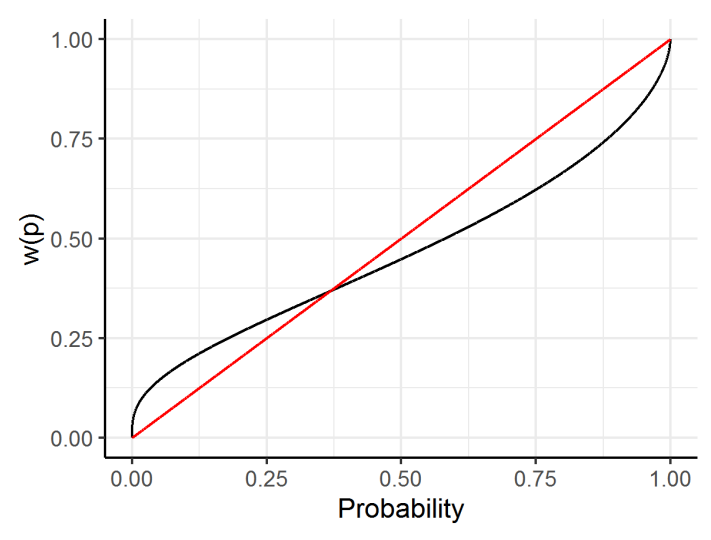

(b) Prelec probability weighting function

Figure 1: Functional forms of the utility and prelec functions under prospect theory.

Notes: This figure shows the functional form of the utility function under prospect theory and of the prelec weighting function. In the figure, the utility function takes the following values for each of its variables; $\theta=0.5$, $\gamma=0.5, \rho=0.5, y_{1}=(0: 1000), y_{0 i}=0$. At the same time the values of the prelec function are; $\alpha=0.5$ and $B=0.5$.

condition" under prospect theory (eq. 4).

$$
w(p)\left[-\theta\left(y_{c}-\beta F-y_{0}\right)^{-\rho}\right]+w(1-p)\left[\left(y_{c}-y_{0}\right)^{\gamma}\right]>u\left(y_{n c}-y_{0}\right)
$$

where the probability of committing a crime depends on the weighted utility of criminal activity $u($ crime $)=w(p)\left[-\theta\left(y_{0}-y_{c}-\beta F\right)^{-\rho}\right]+w(1-p)\left[\left(y_{0}-y_{c}\right)^{\gamma}\right]$ and the utility of withholding from committing the offence $u\left(y_{0}-y_{n c}\right)$. For simplification, and without loss of generality, I assume that the income from not committing the crime $\left(y_{n c}\right)$ and the reference point for elicitation $\left(y_{o}\right)$ are equal to zero. Under these assumptions, equation 3 reduces to equation 5. In it, a person commits a crime if the utility from doing so is greater than zero.

$$
w(p)\left[-\theta\left(y_{c}-\beta F\right)^{\rho}\right]+w(1-p)\left[\left(y_{c}\right)^{\gamma}\right]>0
$$

In this article, I posit that the level of exposure to pollution can affect the probability of committing a criminal offense through its effect on the likelihood of being caught " $p$," its weighting function " $w(p, \alpha, B)$," the discounting value of future punishment " $\beta$," or the shape of the utility function " $U(\gamma, \theta, \rho)$." For the probability of apprehension, increasing $p$, decreases the utility in the gains section $\left(U_{p} \leq 0 \leftrightarrow F=0\right)$, while rising the disutility from arrest in the losses section $\left(U_{p} \leq 0 \leftrightarrow F \neq 0\right){ }^{3}$ I expect that pollution could only decrease the probability of being caught through lower visibility and adverse shocks to the availability of police officers. Second, regarding the constants determining the shape of the utility function, it is straight

\footnotetext{
${ }^{3}$ Henceforth $x_{y}$ means the derivative of $x$ concerning $y$.
} 
forward to show that $U_{\gamma} \geq 0, U_{\rho} \leq 0$, and $U_{\theta} \leq 0$. Higher $\theta$ makes criminals more risk-averse, higher $\gamma$ raises the marginal utility in the gains section and makes the criminal more risk-prone, while higher $\rho$, deepens the marginal disutility in the losses section and leads to more riskaverse behaviors. Third, concerning the discounting factor $\beta$, it is quite intuitive that increasing the discounting of future punishment decreases the utility from committing a crime $\left(U_{\beta} \leq 0\right)$. Finally, air pollution can also change the way individuals assess probabilities. Modifying the parameters of the prelec weighting function $B$ and $\alpha$ shows that if we increase either, the weighted likelihood of being caught decreases, increasing the losses from the cost side of the utility function and increasing the utility in the gains side; $w(p)_{\alpha, B} \leq 0 \wedge w(1-p)_{\alpha, B} \geq 0$.

This theoretical background on the individual decision to become a criminal brings forward a meaningful conclusion. The decision to commit a crime is a complicated process that can be affected by several pathways. For instance, an external shock can modify individual behavior by changing the probability of detection, the way individuals weight this probability, the discounting of future punishments, or the shape of the utility function. In the empirical section, I attempt to explore which of these paths can be confirmed by the empirical evidence.

\subsection{The match of criminals and crimes}

The realization of criminal activities is not only a function of the individual decision to commit a crime but also of the environment where the crime takes place. For instance, even if a criminal experiences a positive utility from illegal activities, she still requires certain market conditions to exist before pursuing these activities. As such, I posit that pollution does affect not only the individual propensity to transgress but also the matching between criminals and crime opportunities. I use a simplified search and matching frictions model as in (Mortensen and Pissarides, 1994) to exemplify the relationship between air pollution and this matching. Importantly, this study is the first to model the effect of air pollution on the matching between criminals and crime opportunities, contributing to the theoretical connection between both variables, and allowing me to shed some light on the impact of air pollution on different crime categories.

Imagine a market for criminal activities like pick-pockets in a subway station. In this market, felons face a given probability of getting caught $(\pi)$, a financial fine after apprehension $(F)$, fixed costs of searching for victims $(b)$, an exogenous destruction rate of matches $(\lambda)$, a discount rate (r), and income from a successful crime (y). In this framework, criminals (c) find victims $(v)$ through the matching technology $m(c, v)$. This technology has the same 
characteristics as a traditional search and matching frictions function in labor markets literature, i.e., it is strictly increasing in both of its parameters, strictly concave, and exhibits constant returns to scale. Image 2 (a) shows the graphic representation of such a function and image 2 b) the theoretical relationship between air pollution and the number of victims and criminals in the market. As noted in figure $2 \mathrm{~b}$, the number of agents in the market decreases as the concentration of air pollution increases. I justify this theoretical assumption with the large number of empirical papers finding a positive effect of air pollution on labor absences (Hanna and Oliva, 2015; Aragon et al., 2016), school absenteeism (Currie et al., 2009; Chen et al., 2018), and avoidance behavior during periods of acute exposure to air contaminants (Zivin and Neidell, 2009).

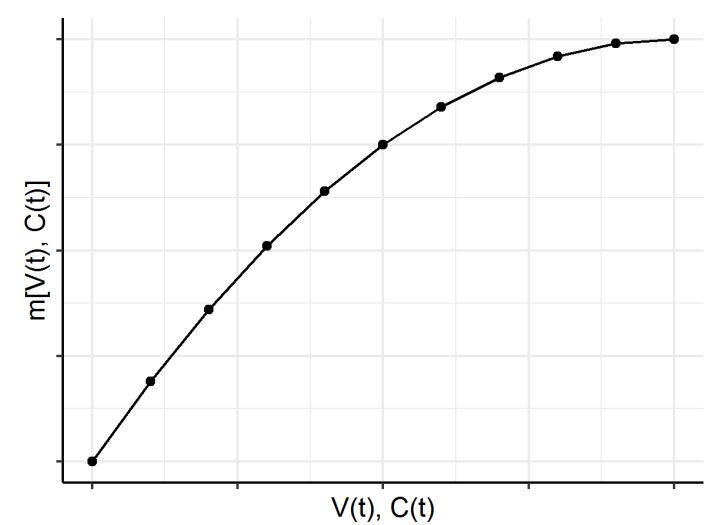

(a) Relationship of the matching function with the number of victims and criminals

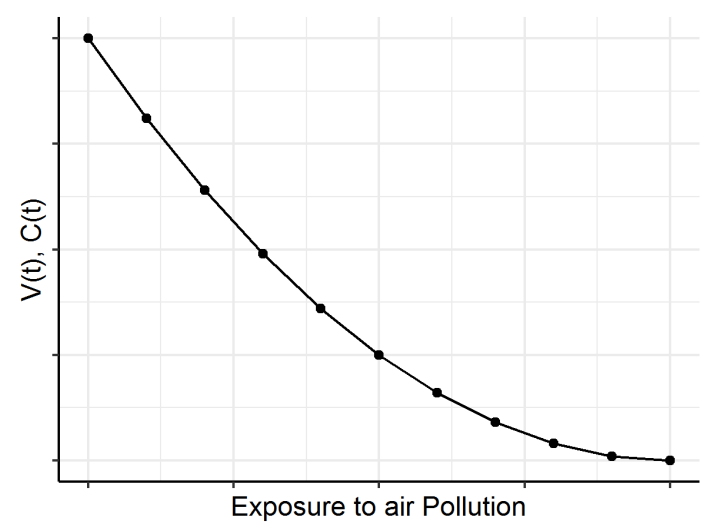

(b) Relationship between exposure to air pollution and the number of victims and criminals

Figure 2: The matching function and the effects of pollution on market agents

The following analysis explores how changes in air pollution affect the tightness of the market for criminal activities and, consequently, the total number of crimes in the market. In steady-state, the tightness of the market can be defined as $\theta=\frac{v}{c} !^{4}$ If pollution affects the number of criminals and victims in the market, it follows that it affects the tightness of the market through $\theta=f(\Pi)$. The behavior of this function is difficult to predict as it depends on the initial ratio between victims and criminals as well as the specific effect pollution would have on each group. In this framework, I assume there are always more victims than criminals, and that the impact of air pollution on victims is larger than on criminals, i.e., air pollution increases the morbidity, mortality, and avoidance behavior of victims more than for criminals.

Felons match with victims through a Poisson process of rate $\frac{m(c, v)}{v}=q(\theta)$. If we assume

\footnotetext{
${ }^{4}$ In the steady-state all variables remain time constant.
} 
a Cobb-Douglas matching function of the form $m(c, v)=A c^{\alpha} v^{1-\alpha}$, the flow probability of criminals is equal to $A \theta^{\alpha} \sqrt[5]{5}$ When the market has more victims than criminals and air pollution affects victims more than criminals, then $\theta_{\Pi} \leq 0$, and conversely, $q_{\Pi} \leq 0 i$. ${ }^{6}$ This outcome means that with higher pollution, the flow probability of criminals (the chance a felon would match with a victim) decreases.

Now that it is clear how air pollution can affect the market tightness and the flow probability of criminals and victims, it is necessary to explore how it can affect the surplus from criminal activities and the number of crimes in the model. The value function for a matched criminal is equal to $r C^{m}=y-\lambda\left[C^{m}-C^{u}\right]-\pi F$, where $y$ represents the income from the felony, $\lambda$ the exogenous match destruction rate, $\left[C^{m}-C^{u}\right]$ the match surplus, $\pi$ the probability of getting caught, and $F$ the losses from apprehension. For an unmatched criminal, the value function is equal to $r C^{u}=-b+q(\theta)\left[C^{m}-C^{u}\right]$, where $b$ represent the costs of actively looking for a crime opportunity. With these two functions it is possible to determine the surplus of the matched criminal $\left(C^{m}-C^{u}\right)$ as a function of their parameters: $S=\frac{y-\pi F-r C^{U}}{r+\lambda+\pi}$. Further, because we are in the steady-state, we have that the flow of matches should remain constant in the sense that the destruction and creation of matches must be equal: $(\pi+\lambda)\left(C^{m}-C^{u}\right)=q(\theta)\left(C^{m}-C^{u}\right)$. Under these conditions, the first derivative of the criminal's surplus concerning $\theta$ is always less than zero; $S_{\theta} \leq 0$. Intuitively, increasing the tightness of the market reduces the surplus from a matched criminal because it increases the flow probability of matches for the unmatched and thus the value of unmatched criminals rise. 7 If we continue assuming that air pollution affect victims more than criminals, and that there are more victims than criminals, we have that, $S_{\Pi}>0$. Thus, air pollution increases the surplus of each match by decreasing the flow probability of criminals and, consequently, the value of an unmatched felon.

So far, I show how air pollution can affect the flow probability of criminals and their surplus from finding a match - even if the only variables affected by air pollution are the pool of criminals and victims in the market. However, it is still necessary to derive a final expression for the effect of pollution on the total number of crimes. As the market is in steady-state, the flow of matched and unmatched victims $\left(V^{m}, V^{u}\right)$ should remain constant. I can express the equality between these flows by multiplying the flow probability of victims, $\theta q(\theta)$, with the

\footnotetext{
${ }^{5} \mathrm{~A}$ is a proxy for the criminal's effort.

${ }^{6}$ It is important to keep in mind that decreasing the market tightness decreases the flow probability of criminals; $q_{\theta}=\alpha A \theta^{\alpha-1} \geq 0$.

${ }^{7} S_{\theta}=\frac{-A \alpha\left(y-\pi F-r C^{u}\right) \theta^{(\alpha-1)}}{\left.\left.\left(\alpha \theta^{\alpha}\right)+r\right)^{2}\right)}$
} 
number of unmatched victims and the match destruction rates with the number of matched persons: $\theta q(\theta) V^{u}=(\pi+\lambda) V^{m}$. The sum of unmatched and matched victims must add to the total number of victims in the market: $V^{u}+V^{m}=V$. Using these two expressions the number of matched victims is equivalent to $V^{m}=\frac{\theta q(\theta)}{\theta q(\theta)+\pi+\lambda} V$, which is also a function of the probability of finding a match and, as a consequence, of air pollution. Moreover, $V_{\theta}^{m} \geq 0$. Implying that as the market tightness grows, the number of match victims also rises. As with the flow probability and the surplus from matching, I assume that there are more victims than criminals and that the impact of pollution on victims is more pronounced than on criminals; as such, $V_{\Pi}^{m} \leq 0 \Leftrightarrow v>c \wedge v_{\Pi}>c_{\Pi}$, implying that as air pollution increases, the number of matches (crimes) decreases.

The search-and-matching frictions model shows that the existence of a crime is not only a function of the individual decision to commit an offense but also on the environment where the criminal prowls. As such, even if the utility from criminality is higher than zero, it may be that pollution reduces the tightness of the market, diminishing the number of matches, thus lowering the number of crimes in periods of high pollution. In principle, the same theoretical framework applies when there are more criminals than victims in a market, and when the impact of pollution on criminals is higher.

\section{Data}

I obtain data on criminal activity from the open data portal websites of Los Angeles (LA, 2020), Mexico City (CDMX, 2020) : $^{8}$ New York City (NYC, 2020), and Toronto (TPS, 2020). For the American cities, the portal contains data on each processed criminal offense within city limits as provided by the New York and Los Angeles police departments. Both data sets include the hour of the crime, its geographical location, the reported date, the crime description, the description of the premises, weapon used, as well as the race, age, and sex of the victim. Additionally, Los Angeles contains the ethnicity, age, and gender of the felon. For Toronto and Mexico City, the data sets are less broad than for Los Angeles and New York. Specifically, both data sets have no information on the crime weapon or the characteristics of the victims and suspects, while Mexico City also lacks the premise where the crime occurred.

There is data for New York City between 2006 and 2018, for Los Angeles between 2010

\footnotetext{
${ }^{8}$ For Mexico City; I compliment the public data with a citizen request for the years between 2012 and 2015
} 
and 2018, for Mexico City between 2012 and 2019, and for Toronto between 2014 and 2018. In total, Los Angeles contains 1,854,292 offenses, New York 5,995,453, Mexico City 1,599,559, and Toronto 166,853,9 Because of different crime classifications, I classify all offenses into twelve subgroups: homicide, manslaughter, rape, robbery, aggravated assaults, non-aggravated assaults, burglary, sex crimes, liberty crimes, larceny, fraud, and other. Abo Law, a Vancouver based Canadian law firm specializing in common and civil law reviewed the classification. ${ }^{10}$ Table 10 of the appendix defines each crime category, and tables $11,12,13$, while 14 show the classification of each crime for each urban center.

Figure 3 shows the hourly, daily, monthly, and yearly variation in the number of crimes across all four cities. First, hourly behavior is very similar, with lower values in the late night and a significant peak at midday, especially in Mexico City and Los Angeles. At the monthly level, all four cities experience a sharp drop in February and an increase in criminality during the warmest months of the year between May and October. Concerning weekday variation, crimes are significantly lower during the weekends, but higher on Fridays. Regarding long-term trends, Mexico City presents a steep increase over the last years of the sample, Los Angeles and Toronto also experience increments, although to a lesser degree than Mexico City, and New York shows a steady decline throughout the observation period. Finally, the most common types of crimes in the sample are larceny $(27.1 \%)$, sex crimes (16.20\%), and non-aggravated assaults $(13.8 \%)$.

It is also important to point out the shortcomings of the data sets on criminality. First, as is typical with empirical analyses of criminal behavior, the data only contain information on reported felonies. This issue is problematic for certain types of crime as sexual offenses, where social stigmatization may drive some victims to avoid the legal process of reporting. However, as I rely on hourly variations, as long as the reporting of events correlate strongly with the actual crimes, this issue should not affect the conclusions of the study. Another problem is that we only observe the level of pollution in the vicinity of the offense. The argument is that criminals may have experienced different levels of air pollution throughout the day, and thus the level of exposure at the time of the event may be uncorrelated with their real experience. Unfortunately, I only have information on the location of the felon at the time and place of the crime and, consequently, I cannot control for the level of exposure before the event.

\footnotetext{
${ }^{9}$ Toronto has substantially less information because the city only reports open-data statistics for a hand full of crimes. The list of crimes is in the appendix, table 12

${ }^{10} \mathrm{Abo}$ Law is found online at https://www.abolaw.ca/. The company specializes in Latin-American and international law. Email: info@abolaw.ca, Phone: +1-604-440-0904.
} 


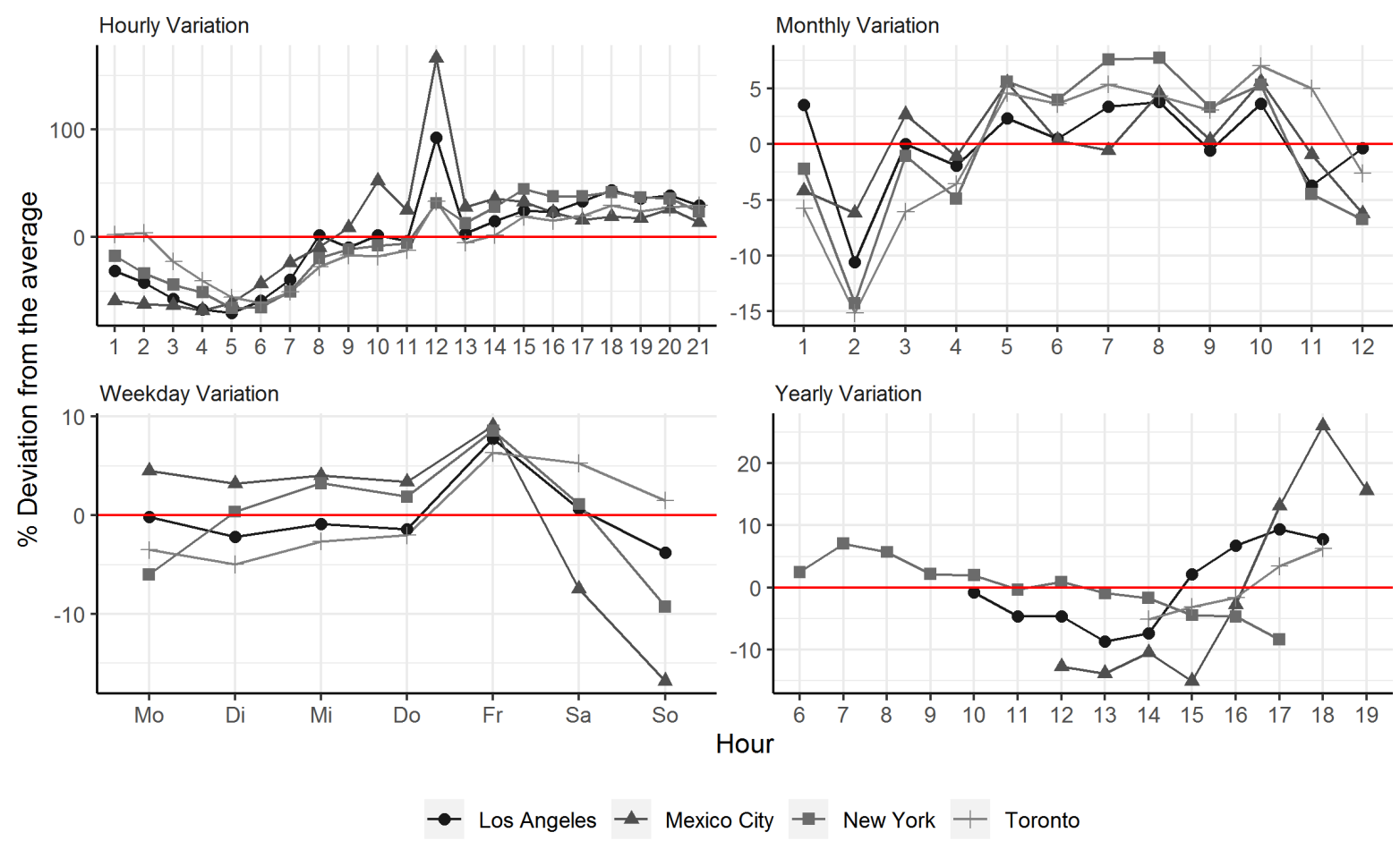

Figure 3: Temporal variation in crime rates

Notes: The grid shows the temporal behavior of criminality in Los Angeles, New York City, Toronto, and Mexico City. Clockwise it shows the hourly, monthly, daily, and yearly variation concerning the average. The data sets for each figure come from the New York City open Data portal (NYC, 2020), Los Angeles open data portal (LA, 2020), Mexico City open data portal (CDMX, 2020), and Toronto public safety data portal (TPS, 2020).

Data on air pollution comes from the monitoring stations of the United States Environmental Protection Agency (EPA, 2020), the center for atmospheric information of Mexico City (Aire, 2020), and the Canadian National Air Pollution Program (NAPS, 2020). All three institutions measure the hourly concentration of $\mathrm{CO}, \mathrm{O}_{3}, \mathrm{NO}_{2}, \mathrm{PM}_{25}, \mathrm{PM}_{10}$ and $\mathrm{SO}_{2}$. There are a total of 24 different stations in the metropolitan area of Los Angeles, 27 in Mexico City, 7 in Toronto and 9 in New York City. Table 1 shows the main descriptive statistics of each contaminant. Furthermore, image 4 plots the temporal behaviour of $\mathrm{CO}, \mathrm{O}_{3}, \mathrm{PM}_{25}$, and $\mathrm{SO}_{2}$ for each urban center.

For $\mathrm{CO}, \mathrm{PM}_{25}$, and $\mathrm{SO}_{2}$, Mexico City shows higher concentrations, while for $\mathrm{O}_{3}$, the highest level changes between Los Angeles and Mexico City depending on the time window. Concerning the temporal behavior of each particle, all four cities exhibit similar seasonal patterns; $\mathrm{CO}, \mathrm{PM}_{25}$, and $\mathrm{SO}_{2}$ are higher during the winter, weekdays, and peak traffic hours, at the same time $\mathrm{O}_{3}$ behaves contrary to traffic contaminants because of its chemical interaction with nitrogen oxides and solar radiation. On average, $\mathrm{O}_{3}$ levels are higher during the summer, after- 
Table 1: Summary statistics of measured contaminants

\begin{tabular}{lccccc}
\hline Pollutant & Units & Mean & Standard Deviation & Maxima & Minima \\
\hline & & & & & \\
Carbon Monoxide & $\mathrm{ppm}$ & 0.53 & 0.44 & 10 & -0.4 \\
Fine Particle Matter & $\mu \mathrm{m}^{3}$ & 14.2 & 12.5 & 690 & -10 \\
Coarse Particle Matter & $\mu \mathrm{m}^{3}$ & 36.9 & 25.1 & 707 & -20 \\
Nitrous Dioxide & $\mathrm{ppb}$ & 22.6 & 14.3 & 190 & -4.8 \\
Sulfur Dioxide & $\mathrm{ppb}$ & 3.5 & 6.9 & 260 & -1.5 \\
Ozone & $\mathrm{ppm}$ & 27.4 & 23.2 & 210 & -3.0 \\
\hline
\end{tabular}

Notes: The data for New York City and Los Angeles come from the US Environmental Protection Agency (EPA, 2020), for Mexico city from the Center for Atmospheric Information of Mexico City (Aire, 2020), and for Canada from the Canadian National Air Pollution Program (NAPS, 2020). Acronyms; ppm is particles per million, $p p b$ particles per billion, and $\mu \mathrm{m}^{3}$ micrograms per cubic meter

noons, and weekends. Regarding the long term behavior of each particle, for all air pollutants except for $\mathrm{O}_{3}$, cities exhibit a downward trend in their yearly concentrations, while for $\mathrm{O}_{3}$, the contrary occurs.

Finally, weather data comes from thirteen monitoring stations of the National Oceanic and Atmospheric Administration (NOAA), three stations from the government of Canada historical weather data, and thirteen measuring stations for Mexico City. I use temperature, rain, and relative humidity as covariates and wind direction as an instrument.

\section{Empirical Strategy}

I assign crimes to stations by adding the number of crimes happening in a two kilometer radius around each station. To infer causality, I exploit the high temporal granularity and spatial heterogeneity of the data set. This temporal granularity and spatial heterogeneity allow me to ensure the exogeneity of the causal contaminant with the use of time and spatial fixed effects in the form of yearly, monthly, weekday, hourly, and station fixed effects. Temporal fixed effects allow capturing the inter-hour, inter-weekday, inter-month, and inter-year variation in the dependent variable, while station fixed-effects control for time consistent relevant unobservables. It is crucial to consider time effects because people may be more prone to commit crimes during specific time-windows like weekends, Christmas, or summers. Further, station fixed effects are necessary because if pollution is higher in areas with less police control and lower sociodemographic status, a simple cross-sectional approach would likely overestimate its impact on criminality. Additionally, I also control for relevant weather covariates like temperature and relative humidity that could affect both the level of air pollution and the propensity for criminal 


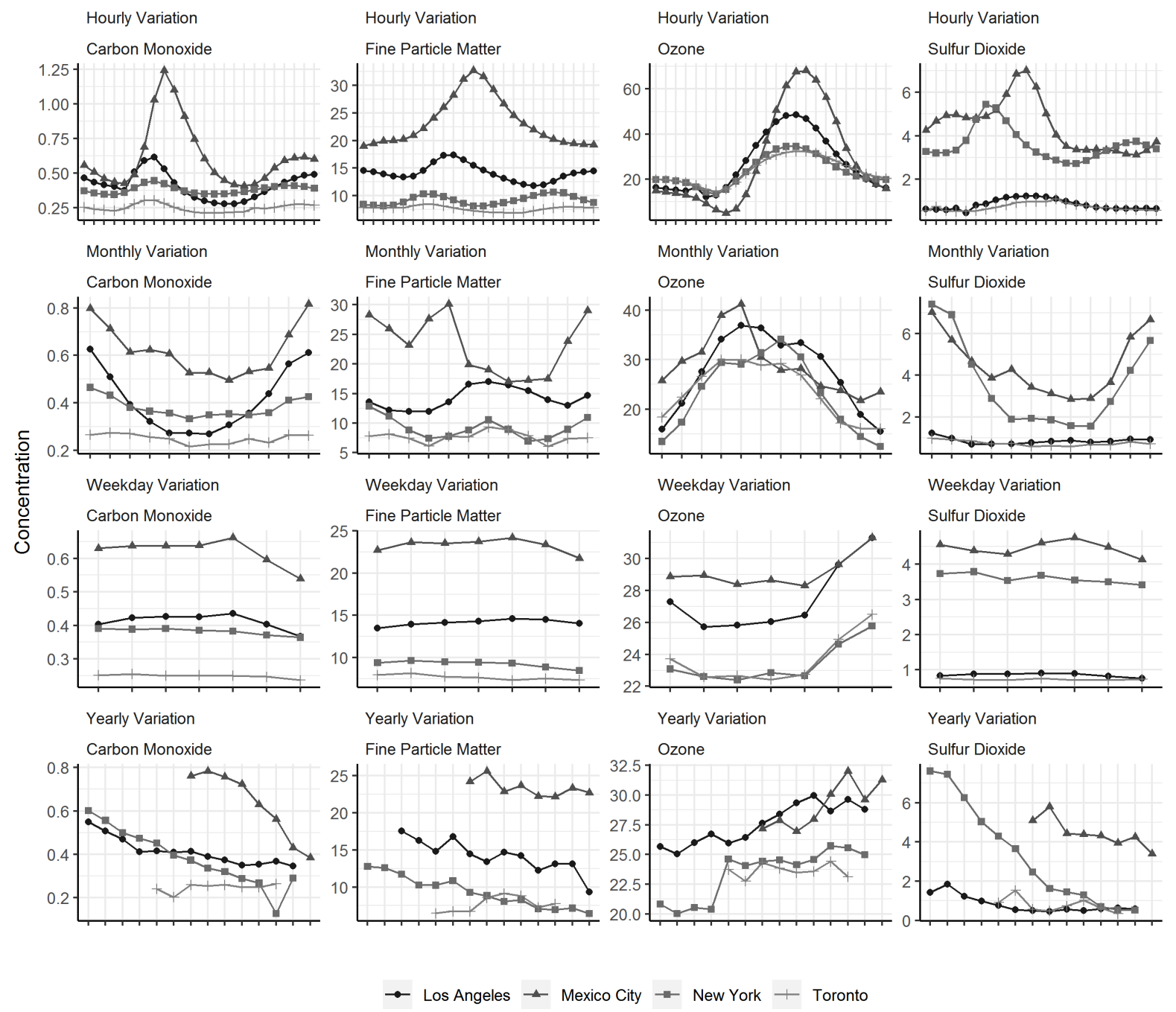

Figure 4: Temporal variation in air pollution

Notes: Because of space constraints, I omit the x-axis. However, the hourly variations start at midnight and end at 23:00 hrs. Monthly variation starts in January and ends in December. For weekdays, it starts with Monday and ends with Sunday. Years start with 2006 and ends with 2019. The data for New York City and Los Angeles come from the US Environmental Protection Agency (EPA, 2020), for Mexico city from the Center for Atmospheric Information of Mexico City (Aire, 2020), and for Canada from the Canadian National Air Pollution Program (NAPS, 2020)

activities. Still, even after controlling for all previously mentioned variation, there may be unobservables like traffic biasing the point estimates of the ordinary least squares regression. To deal with this, and following Bondy et al. (2020); Herrnstadt et al. (2016), and Herrnstadt and Muehlegger (2015), I use an IV approach using wind direction as an instrument under the assumption that the only way by which the direction of the wind influence criminality is through its effect on air pollution. Furthermore, even when wind direction is seasonal across all four cities, the hour to hour variation is substantial enough to treat it as exogenous.

Once I implement panel techniques, exploit the hourly granularity of the data set, control 
for time-varying weather-observables, and use instrumental variable models, I assume that the effect of air pollution on criminality is exogenous. Additionally, I account for the withincluster correlation of standard errors by clustering them at the station level. Equation 6 shows the functional form of the ordinary least squares regression.

$$
\log \left(C_{c t}^{j}\right)=\gamma_{i} P o l_{c t}^{i}+\gamma_{2} X_{c t}+\Omega_{t}+\lambda_{c}+\varepsilon_{c t}
$$

In it, $C_{c t}^{j}$ measures the number of crimes in category $j$ happening within the two kilometers radius around station $c$ at time $t$. $P o l_{c t}^{i}$ is the value of pollutant $i$ at station $c$ at time $t . X_{c t}$ is the matrix of weather covariates. $\Omega_{t}$ is a matrix of time fixed effects controlling for the hour, weekday, month, and year when the crime happened. $\lambda_{c}$ controls for the stations where the felony occurred, and $\varepsilon_{c t}$ is an idiosyncratic and orthogonal error term.

Equations 7 and 8 show the econometric specification of the IV design. Precisely, equation 7 portrays the first stage regression of each pollutant on all the covariates of equation 6 plus wind direction $w d r_{i}$, and equation 8 exhibits the second stage regression using the fitted values $\left(\hat{P o l}_{c t}^{i}\right)$ from equation 7 as the causal variable.

$$
\begin{gathered}
\hat{P o l_{c t}^{i}}=\rho w d r_{i}+\gamma_{2} X_{c t}+\Omega_{t}+\lambda_{c}+\mu_{c t} \\
\log \left(C_{c t}^{j}\right)=\gamma_{i} \hat{P o l}_{c t}^{i}+\gamma_{2} X_{c t}+\Omega_{t}+\lambda_{c}+\varepsilon_{c t}
\end{gathered}
$$

\section{Results}

\subsection{Total Crimes}

Table 2 shows the point estimates of the ordinary least squares design. The point estimates correspond to the effect of six different contaminants on the total number of crimes happening across all sixty-seven stations. The design shows positive and significant point estimates for three prominent traffic-related particles, $\mathrm{CO}, \mathrm{NO}_{2}$, and $\mathrm{PM}_{25}$, while remaining insignificant for $\mathrm{O}_{3}, \mathrm{PM}_{10}$, and $\mathrm{SO}_{2}$. The estimates of the table are the effect of marginally increasing each contaminant on the number of hourly crimes happening in the two-kilometer radius around each monitoring station. For simplicity, I henceforth present each point estimate as a percentage change after increasing its concentration by one standard deviation. For $C O$, increasing its level by one standard deviation increases the number of crimes in the two kilometers radius around the monitoring station by $1.84 \%$. for $\mathrm{NO}_{2}$ and $P M_{25}$ the same increment does it by 
$1.58 \%$ and $1.75 \%$ respectively. It is important to notice that these three particles usually come from traffic; as such, their correlation is quite significant at the hourly level. Table 16 in the appendix shows the hourly correlation between all contaminants. This high level of interparticle correlation hinders the claim that only one of these contaminants is responsible for the effect. In general, the results from this first regression show three interesting insights; first, the effect of ozone on criminal activity is insignificant, which is contrary to the significant impact found by Herrnstadt et al. (2016) on daily variation in Los Angeles. Second, the result for fine particle matter resembles the 2.2\% deviation found by Herrnstadt and Muehlegger (2015) in Chicago, and third, this is the first estimate of the effect of carbon monoxide, nitrogen dioxide, and sulfur dioxide on criminal behavior.

Table 2: OLS regressions for each contaminant

\begin{tabular}{lcccccc}
\hline & \multicolumn{7}{c}{ Dependent variable: Log of Total Crimes } \\
\cline { 2 - 7 } & $\mathrm{CO}$ & $\mathrm{NO}_{2}$ & $\mathrm{O}_{3}$ & $\mathrm{PM}_{10}$ & $\mathrm{PM}_{25}$ & $\mathrm{SO}_{2}$ \\
\hline & 0.0411 & 0.0011 & -0.0008 & 0.0002 & 0.0014 & -0.0005 \\
& $(0.0137)$ & $(0.0003)$ & $(0.0006)$ & $(0.0002)$ & $(0.0003)$ & $(0.0004)$ \\
\hline R-squared & 0.54 & 0.54 & 0.58 & 0.57 & 0.59 & 0.56 \\
Std. Dev. & 0.44 & 14.3 & 23.2 & 25.1 & 12.5 & 6.9 \\
No. Obs. & $1,341,129$ & $1,388,774$ & $1,665,356$ & 705,308 & $1,972,184$ & $1,174,688$ \\
\hline
\end{tabular}

Notes: This table show the point estimates of an ordinary least squares regression on the number of crimes happening in a two kilometer radius around the monitoring stations in the sample. The specification contains, year, month, weekday, and hour temporal fixed effects as well as station fixed effects and weather covariates. Standard errors are clustered at the station level

Even after controlling for the large battery of temporal fixed effects, there is still the possibility that unobserved covariates would bias the coefficients of the regression design especially when we only find significance for contaminants directly related to traffic. For example, irregular peaks in traffic could increase pollution while at the same time increasing the probability of crimes through matching and uncomfortable situations that may push people into a stage of over-excitement and aggressiveness. To control for the possible interference of these unobserved covariates I use the IV specification. Table 9 of the appendix shows the coefficients of the first stage regression for the four urban centers in the data-set and the different contaminants under study. The effect of wind direction on all particles is highly significant across all urban agglomerations. Table 3 shows the results from the IV design, the regressions derive significance for three particles, $\mathrm{O}_{3} \mathrm{CO}$, and $\mathrm{NO}_{2}$. Increasing their concentration by one 
standard deviation rises the number of crimes in the vicinity of monitoring stations by $11.37 \%$, $5.57 \%$, and $7.04 \%$, respectively ${ }^{11}$ The results using wind as an instrumental variable show the importance of controlling for unobservables, especially for ozone, where the new estimate is now in line with the positive increment found by Herrnstadt et al. (2016) in Los Angeles and (Burkhardt et al. 2019) across a large number of American counties. This change in significance points towards the importance of instrumenting the regression design, as the negative correlation between ozone and traffic contaminants blurred the negative relationship between this particle and crime. Concerning the other contaminants, the IV design spurs no significance.

Table 3: Instrumental variable regression for each contaminant

\begin{tabular}{lcccccc}
\hline & \multicolumn{6}{c}{ Dependent variable: Log of Total Crimes } \\
\cline { 2 - 7 } & $\hat{\mathrm{CO}}$ & $\mathrm{NO}_{2}$ & $\hat{\mathrm{O}}_{3}$ & $P \hat{M}_{10}$ & $P \hat{M}_{25}$ & \multicolumn{1}{c}{$\hat{\mathrm{O}}_{2}$} \\
\hline & 0.1244 & 0.0045 & 0.0049 & -0.0010 & 0.0038 & -0.0216 \\
& $(0.0650)$ & $(0.0026)$ & $(0.0022)$ & $(0.0027)$ & $(0.0030)$ & $(0.0251)$ \\
\hline R-squared & 0.5396 & 0.5377 & 0.5679 & 0.5710 & 0.5873 & 0.4896 \\
Std. Dev. & 0.44 & 14.3 & 23.2 & 25.1 & 12.5 & 6.9 \\
No. Obs. & $1,322,279$ & $1,369,688$ & $1,642,985$ & 690,859 & $1,954,717$ & $1,156,599$ \\
\hline
\end{tabular}

Notes: This table shows the point estimates of an instrumental variable regression design on the number of crimes happening in a two-kilometer radius around the monitoring stations. The instrumental variable to capture the effect of pollution on crime is wind direction. The specification contains, year, month, weekday, and hour temporal fixed effects as well as station fixed effects and weather covariates. Standard errors clustered at the station level.

So far, I show evidence that increments in the concentration of air pollution increase criminality in the vicinity of monitoring stations for $\mathrm{CO}, \mathrm{NO}_{2}$, and $\mathrm{O}_{3}$. However, this approach may appear naive if we do not take into consideration the characteristics of each crime. For instance, Herrnstadt et al. (2016) proposes that if air pollution increases aggressive behavior, it will only affect violent felonies. Another possibility is that pollution increases the eagerness for reward and thus the number of unpremeditated crimes. More importantly, air pollution could have different effects across crime categories. If exposure increases some crime-types while decreasing others, the impact on the total number of crimes could shadow interesting mechanisms in each category. In the next sections, I exploit the different crime typologies to understand the pathways through which air contaminants affect criminality.

\footnotetext{
${ }^{11}$ The effect of $\mathrm{pm}_{25}$ is borderline significant, an outcome that rise in relevance for the forthcoming sections
} 


\subsection{Heterogeneous Effects Across Crime Categories}

First, Herrnstadt et al. (2016), Burkhardt et al. (2019), and Herrnstadt and Muehlegger (2015) propose that air pollution particularly increases criminality for violent crimes. To understand this connection, I divide criminal offenses into violent (Homicide, Aggravated Assault, Robbery, and Rape) and non-violent (Burglary, Larceny, Fraud, Forgery, and Bribery).12

Table 4 shows the results of the IV design for both categories. For violent crimes, the point estimates of $\mathrm{CO}, \mathrm{NO}_{2}, \mathrm{PM}_{25}, \mathrm{PM}_{10}$, and $\mathrm{O}_{3}$ appear significant. The coefficients imply an increase after rising each particle by one standard deviation of $4.38 \%, 5.03 \%, 6.13 \%, 4.53 \%$, and $8.12 \%$, respectively. Only for $\mathrm{SO}_{2}$, I find no significant point estimate. Regarding nonviolent crimes, I do not find any significant coefficient, although the borderline significant coefficients for particle matter suggest a negative relationship. These effects confirm the results of Burkhardt et al. (2019) and Herrnstadt et al. (2016) on the more pronounced impact of pollution on violent offenses.

Table 4: Instrumental variable regression across violent and non-violent crimes

\begin{tabular}{|c|c|c|c|c|c|c|}
\hline & \multicolumn{6}{|c|}{ Dependent variable: Log of Number of Crimes } \\
\hline & $\hat{C O}$ & $\mathrm{NO}_{2}$ & $\hat{O}_{3}$ & $P \hat{M}_{10}$ & $P \hat{M}_{25}$ & $S \hat{O}_{2}$ \\
\hline Violent Crimes & $\begin{array}{c}0.0979 \\
(0.0346)\end{array}$ & $\begin{array}{c}0.0035 \\
(0.0014)\end{array}$ & $\begin{array}{c}0.0035 \\
(0.0011)\end{array}$ & $\begin{array}{c}0.0018 \\
(0.0009)\end{array}$ & $\begin{array}{c}0.0049 \\
(0.0010)\end{array}$ & $\begin{array}{l}-0.0194 \\
(0.0190)\end{array}$ \\
\hline Non Violent Crimes & $\begin{array}{l}-0.0296 \\
(0.0484) \\
\end{array}$ & $\begin{array}{l}-0.0011 \\
(0.0016) \\
\end{array}$ & $\begin{array}{l}-0.0008 \\
(0.0015) \\
\end{array}$ & $\begin{array}{l}-0.0043 \\
(0.0028) \\
\end{array}$ & $\begin{array}{l}-0.0038 \\
(0.0024) \\
\end{array}$ & $\begin{array}{c}0.0099 \\
(0.0147) \\
\end{array}$ \\
\hline Std. Dev. & 0.44 & 14.3 & 23.2 & 25.1 & 12.5 & 6.9 \\
\hline
\end{tabular}

Notes: This table shows the point estimates of an instrumental variable regression design on the number of violent and non-violent crimes happening in a two-kilometer radius around the monitoring stations. The instrumental variable to capture the effect of pollution on crime is wind direction. The specification contains, year, month, weekday, and hour temporal fixed effects as well as station fixed effects and weather covariates. Standard errors clustered at the station level.

However, even when we find positive estimates for violent crimes, it may be that it is not the brutal characteristics of the offense that drives the effect, but the unpremeditated nature of violent felonies. To disentangle the violent nature of the crime from its unpremeditated exercise, I select unpremeditated crimes that are similar regarding the goal of the criminal, but that vary in the level of exercised violence. For this, I run the regression on two property crimes

\footnotetext{
${ }^{12}$ There is the possibility that burglaries may come with a degree of violence. However, I presume the objective of most burglary cases is to avoid facing the victims.
} 
(robbery and larceny) and two aggression offenses (aggravated and non-aggravated assaults). The core idea of this exercise is to see if there are different effects among unpremeditated crimes based on their level of violence, as, if the violent nature of the felony is behind the significance, we would expect to find more robust coefficients for aggravated assault and robbery than for non-aggravated assault and larceny. Table 5 shows the point estimates for these four crime categories.

Table 5: Instrumental variable regression for aggravated assaults, non-aggravated assaults, larcenies, and robberies

\begin{tabular}{lcccccc}
\hline & \multicolumn{7}{c}{ Dependent variable: Log of Number of Crimes } \\
\cline { 2 - 7 } & $\hat{C O}$ & $\mathrm{NO}_{2}$ & $\hat{\mathrm{O}}_{3}$ & $\hat{P M}_{10}$ & $\mathrm{PM}_{25}$ & $\hat{S O}_{2}$ \\
\hline \multirow{2}{*}{ Aggravated assaults } & 0.0605 & 0.0022 & 0.0021 & 0.0013 & 0.0031 & -0.0130 \\
& $(0.0228)$ & $(0.0010)$ & $(0.0007)$ & $(0.0006)$ & $(0.0007)$ & $(0.0127)$ \\
Non-aggravated assaults & 0.0447 & 0.0015 & 0.0018 & 0.0009 & 0.0027 & -0.0089 \\
& $(0.0183)$ & $(0.0007)$ & $(0.0006)$ & $(0.0006)$ & $(0.0007)$ & $(0.0094)$ \\
Robbery & 0.0408 & 0.0015 & 0.0015 & 0.0005 & 0.0021 & -0.0071 \\
& $(0.0150)$ & $(0.0005)$ & $(0.0004)$ & $(0.0005)$ & $(0.0004)$ & $(0.0073)$ \\
Larceny & 0.1907 & 0.0028 & -0.0022 & 0.0132 & -0.0008 & -0.0658 \\
& $(0.0770)$ & $(0.0014)$ & $(0.0011)$ & $(0.0106)$ & $(0.0048)$ & $(0.0446)$ \\
\hline \multirow{2}{*}{ Std. Dev. } & 0.44 & 14.3 & 23.2 & 25.1 & 12.5 & 6.9 \\
\hline
\end{tabular}

Notes: This table shows the point estimates of an instrumental variable regression design on the number of aggravated assaults, non-aggravated assaults, robberies, and larcenies happening in a two-kilometer radius around the monitoring stations. The instrumental variable to capture the effect of pollution on crime is wind direction. The specification contains, year, month, weekday, and hour temporal fixed effects as well as station fixed effects and weather covariates. Standard errors clustered at the station level.

Concerning aggravated and non-aggravated assaults, the table shows that for aggravated assaults, $\mathrm{CO}, \mathrm{NO}_{2}, \mathrm{O}_{3}, \mathrm{PM}_{10}$, and $\mathrm{PM}_{25}$ remain positive and significant. Increasing their concentration by one standard deviation rises their occurrence by $2.44 \%, 3.30 \%, 5.33 \%, 3.52 \%$, and $4.25 \%$, respectively. For non-aggravated assaults, only the coefficient for $P M_{10}$ stops being significant. For the other particles, however, their point estimates are lower than for aggravated assault, increasing their concentration by one standard deviation boost non-aggravated assaults by $1.68 \%(\mathrm{CO}), 1.79 \%\left(\mathrm{NO}_{2}\right), 4.64 \%\left(\mathrm{O}_{3}\right)$, and $3.62 \%\left(\mathrm{PM}_{25}\right)$. Regarding property crimes, for robbery, the point estimates are positive and significant for $\mathrm{CO}, \mathrm{NO}_{2}, \mathrm{O}_{3}$, and $\mathrm{PM}_{25}$, while for larceny, they are only significant for $\mathrm{CO}$ and $\mathrm{NO}_{2}$. So, analyzing assaults and property crimes by their level of violence suggests a more sensitive reaction to variations in hourly levels of air pollution from brutal offenses, suggesting that one of the pathways through which pollution 
increases crime is by increasing the utility stemming from violent behavior. The results on the positive impact of pollution on assaults are in line with the findings of Burkhardt et al. (2019) and Herrnstadt et al. (2016). However, finding a positive outcome for robberies stands as an additional pathway not previously identified in the literature. Additionally, finding significant point estimates for larceny contradicts the conclusions of Herrnstadt et al. (2016) and Herrnstadt and Muehlegger (2015) that air pollution only affects the occurrence of violent crimes, but agrees with the findings of Bondy et al. (2020) on the positive relationship between pickpocketing and air pollution in London. Discovering that air particles affect not only violent crimes but also unpremeditated non-violent offenses, like larceny, allows us to consider additional mechanisms besides an increased taste for violence as drivers of the relationship between pollution and crime. The increase in the utility of unpremeditated non-violent crimes can occur because of a change in the probability of apprehension, it's weighting, the shape of the utility function, or the discounting of future punishments. 13

Now, it is entirely likely that pollution has very different effects on different crimes. These different consequences come from the aforementioned violent nature of the offense, its temporal elicitation of utility, and the matching between crime opportunities and criminals. For instance, a non-violent property crime like burglary requires, in the majority of cases, an empty house. If, as the literature suggests, air pollution increases school absenteeism, labor absences, and avoidance behavior, it is intuitive to expect that the number of burglaries would decrease because of fewer crime opportunities for burglars. Table 6 shows the point estimates for all the crime categories. First, $C O$ shows positive point estimates for robbery, larceny, aggravated assaults, non-aggravated assaults, and fraud, while, as expected, only negative coefficients for burglary. $\mathrm{NO}_{2}$ find positive estimates for aggravated assaults, non-aggravated assaults, larceny, robbery, and other crimes, along with significant reductions for burglary. $\mathrm{O}_{3}$ increases robbery, aggravated assaults, non-aggravated assaults, fraud, forgery, bribery, and other crimes while also decreasing burglary plus sex crimes and larceny. $P M_{25}$ have positive and significant point estimates for liberty crimes, non-aggravated assaults, aggravated assaults, robbery, and other crimes, while negative and significant for sexual offenses and burglary. $P M_{10}$ only seems to increases aggravated assaults and reduce burglary. Finally, $\mathrm{SO}_{2}$ exhibits no influence in any crime category.

\footnotetext{
${ }^{13}$ In the next section, I analyze different impacts across crime premises and manage to provide evidence that it is not the probability of apprehension that drives the results. Additionally, using the findings of Bondy et al. (2020) I propose that it is also unlikely that pollution would change the utility function into more risk-seeking forms.
} 
Table 6: Instrumental variable regression for all crime categories

\begin{tabular}{|c|c|c|c|c|c|c|}
\hline & \multicolumn{6}{|c|}{ Dependent variable: Log of Number of Crimes } \\
\hline & $\hat{C O}$ & $\mathrm{NO}_{2}$ & $\hat{O}_{3}$ & $P \hat{M}_{10}$ & $P \hat{M}_{25}$ & $S \hat{O}_{2}$ \\
\hline Aggravated Assault & $\begin{array}{c}0.0605 \\
(0.0228)\end{array}$ & $\begin{array}{c}0.0022 \\
(0.0010)\end{array}$ & $\begin{array}{c}0.0021 \\
(0.0007)\end{array}$ & $\begin{array}{c}0.0013 \\
(0.0006)\end{array}$ & $\begin{array}{c}0.0031 \\
(0.0007)\end{array}$ & $\begin{array}{l}-0.0130 \\
(0.0127)\end{array}$ \\
\hline Non-aggravated Assault & $\begin{array}{c}0.0447 \\
(0.0183)\end{array}$ & $\begin{array}{c}0.0015 \\
(0.0007)\end{array}$ & $\begin{array}{c}0.0018 \\
(0.0006)\end{array}$ & $\begin{array}{c}0.0009 \\
(0.0006)\end{array}$ & $\begin{array}{c}0.0027 \\
(0.0007)\end{array}$ & $\begin{array}{l}-0.0089 \\
(0.0094)\end{array}$ \\
\hline Robbery & $\begin{array}{c}0.0408 \\
(0.0150)\end{array}$ & $\begin{array}{c}0.0015 \\
(0.0005)\end{array}$ & $\begin{array}{c}0.0015 \\
(0.0004)\end{array}$ & $\begin{array}{c}0.0005 \\
(0.0005)\end{array}$ & $\begin{array}{c}0.0021 \\
(0.0004)\end{array}$ & $\begin{array}{l}-0.0071 \\
(0.0073)\end{array}$ \\
\hline Larceny & $\begin{array}{c}0.1907 \\
(0.0770)\end{array}$ & $\begin{array}{c}0.0028 \\
(0.0014)\end{array}$ & $\begin{array}{l}-0.0022 \\
(0.0011)\end{array}$ & $\begin{array}{c}0.0132 \\
(0.0106)\end{array}$ & $\begin{array}{c}-0.0008 \\
(0.0048)\end{array}$ & $\begin{array}{c}-0.0658 \\
(0.0446)\end{array}$ \\
\hline Burglary & $\begin{array}{l}-0.0133 \\
(0.0057)\end{array}$ & $\begin{array}{l}-0.0004 \\
(0.0002)\end{array}$ & $\begin{array}{l}-0.0004 \\
(0.0001)\end{array}$ & $\begin{array}{l}-0.0003 \\
(0.0001)\end{array}$ & $\begin{array}{l}-0.0006 \\
(0.0002)\end{array}$ & $\begin{array}{c}0.0030 \\
(0.0031)\end{array}$ \\
\hline Sexual Crimes & $\begin{array}{l}-0.0467 \\
(0.0275)\end{array}$ & $\begin{array}{l}-0.0022 \\
(0.0013)\end{array}$ & $\begin{array}{l}-0.0022 \\
(0.0011)\end{array}$ & $\begin{array}{l}-0.0031 \\
(0.0018)\end{array}$ & $\begin{array}{l}-0.0039 \\
(0.0013)\end{array}$ & $\begin{array}{c}0.0147 \\
(0.0162)\end{array}$ \\
\hline Rape & $\begin{array}{l}-0.0003 \\
(0.0009)\end{array}$ & $\begin{array}{l}-0.0000 \\
(0.0000)\end{array}$ & $\begin{array}{c}0.0000 \\
(0.0000)\end{array}$ & $\begin{array}{l}-0.0002 \\
(0.0002)\end{array}$ & $\begin{array}{l}-0.0002 \\
(0.0001)\end{array}$ & $\begin{array}{c}0.0006 \\
(0.0008)\end{array}$ \\
\hline Homicide & $\begin{array}{l}-0.0008 \\
(0.0007)\end{array}$ & $\begin{array}{l}-0.0000 \\
(0.0000)\end{array}$ & $\begin{array}{l}-0.0000 \\
(0.0000)\end{array}$ & $\begin{array}{l}-0.0000 \\
(0.0000)\end{array}$ & $\begin{array}{l}-0.0000 \\
(0.0000)\end{array}$ & $\begin{array}{c}0.0002 \\
(0.0002)\end{array}$ \\
\hline Mansloughter & $\begin{array}{l}-0.0003 \\
(0.0004)\end{array}$ & $\begin{array}{l}-0.0000 \\
(0.0000)\end{array}$ & $\begin{array}{l}-0.0000 \\
(0.0000)\end{array}$ & $\begin{array}{l}-0.0000 \\
(0.0000)\end{array}$ & $\begin{array}{l}-0.0000 \\
(0.0000)\end{array}$ & $\begin{array}{c}0.0000 \\
(0.0001)\end{array}$ \\
\hline Crimes against liberty & $\begin{array}{c}0.0021 \\
(0.0015)\end{array}$ & $\begin{array}{c}0.0001 \\
(0.0001)\end{array}$ & $\begin{array}{c}0.0001 \\
(0.0000)\end{array}$ & $\begin{array}{c}0.0000 \\
(0.0000)\end{array}$ & $\begin{array}{c}0.0001 \\
(0.0000)\end{array}$ & $\begin{array}{l}-0.0004 \\
(0.0005)\end{array}$ \\
\hline Fraud, forgery, and bribes & $\begin{array}{c}0.0439 \\
(0.0249)\end{array}$ & $\begin{array}{c}0.0010 \\
(0.0008)\end{array}$ & $\begin{array}{c}0.0016 \\
(0.0008)\end{array}$ & $\begin{array}{l}-0.0006 \\
(0.0014)\end{array}$ & $\begin{array}{c}0.0006 \\
(0.0011)\end{array}$ & $\begin{array}{l}-0.0072 \\
(0.0089)\end{array}$ \\
\hline Other & $\begin{array}{c}0.0629 \\
(0.0265) \\
\end{array}$ & $\begin{array}{c}0.0024 \\
(0.0011) \\
\end{array}$ & $\begin{array}{c}0.0025 \\
(0.0009) \\
\end{array}$ & $\begin{array}{c}0.0012 \\
(0.0010) \\
\end{array}$ & $\begin{array}{c}0.0042 \\
(0.0009) \\
\end{array}$ & $\begin{array}{c}-0.0134 \\
(0.0146) \\
\end{array}$ \\
\hline Std. Dev. & 0.44 & 14.3 & 23.2 & 25.1 & 12.5 & 6.9 \\
\hline
\end{tabular}

Notes: This table shows the point estimates of an instrumental variable regression design on the number of each crime category happening in a two-kilometer radius around the monitoring stations. The instrumental variable to capture the effect of pollution on crime is wind direction. The specification contains, year, month, weekday, and hour temporal fixed effects as well as station fixed effects and weather covariates. Standard errors clustered at the station level.

The fact that the table has negative coefficients for burglary and sex crimes allows us to confirm that for some crimes, the theoretical model of search and matching frictions can explain the observed variation. Formally, the number of victims (or crime opportunities) decreases with environmental pollution for burglary and sexual offenses. Notably, this is the first article discussing a negative relationship between air pollution and crime.

The outcomes of this section convey several exciting conclusions. First, there is indeed an influence of air pollutants on the individual decision to commit a crime. For violent offenses, 
I theoretize that this comes from an extra utility stream from violent behavior. However, we can also see a positive, although less potent effect on non-violent offenses, particularly those that are unpremeditated - suggesting that it is not only an increase in the utility stemming from violence but also a change in the weighting of arrest probabilities, the shape of the utility function or the discounting of future punishments. Second, the matching between crime opportunities and criminals also determines the effect of exposure. For two crime categories, it appears that the matching plays a primary role. First, for all contaminants but $\mathrm{SO}_{2}$, burglary exhibits negative and significant coefficients. This outcome is in line with the matching model of section 3.2 , where I discuss the possibility that pollution can change the tightness of the market for criminal activities through varying the number of active felons and crime opportunities. Furthermore, I find an additional outcome worth exploring by the epidemiological literature, $\mathrm{CO}, \mathrm{O}_{3}$, and $P M_{25}$ decrease sexual offenses.

\subsection{Heterogeneous Effects Across Premises}

The data sets of New York City, Los Angeles, and Toronto also contain information on the premise where the crime took place. I exploit this information to check different effects depending on the location of the crime. Table 7 show the impact of all particles across three premises; outside, commercial, and residential. I analyze the effect across premises for the total number of crimes and violent crimes. Table 15 of the appendix shows the classification of premises for each city.

Concerning the total number of crimes, $C O$ exhibits positive coefficients in commercial, residence, and outside premises. $N O_{2}$ only on the outside, and $P M_{10}$ only inside of homes. Regarding violent offenses, for commercial premises, the point estimates are less strong, with only $\mathrm{CO}$ and $\mathrm{O}_{3}$ showing significance, this happens because violent offenses tend to occur in the street or inside residences. For outside and residential premises, the table shows significant and positive coefficients for $\mathrm{CO}, \mathrm{NO}_{2}, \mathrm{O}_{3}$, and $\mathrm{PM}_{25}$. Moreover, the point estimates for crimes happening in the street tend to be higher and more significant than for residences, likely because exposure values in the street are higher than indoors. The fact that we can see significant point estimates across all premises reduces the possibility that changes in the probability of apprehension coming from visibility constraints or reductions in the police force are behind the significant point estimate. Furthermore, these results follow the findings of Burkhardt et al. (2019) on the negative impact of violent crimes on both outside and in-home premises. While 
further contributing to the literature by showing the impact on a new premise (commercial buildings) on a new time window (hourly) and by showing that following the fact that air pollution is higher in the street, criminal activities on the outside increase more than in-home.

Table 7: Instrumental variable regression across different premises for the total number of crimes and the total number of violent crimes

\begin{tabular}{lcccccc}
\hline & \multicolumn{7}{c}{ Dependent variable: Log of Number of Crimes } \\
\cline { 2 - 7 } & $\hat{C O}$ & $\mathrm{NO}_{2}$ & $\hat{\mathrm{O}}_{3}$ & $P \hat{M}_{10}$ & $P \hat{M}_{25}$ & $S \hat{O}_{2}$ \\
\hline \multirow{2}{*}{ Commercial } & 0.0527 & 0.0004 & -0.0004 & 0.0040 & -0.0005 & -0.0191 \\
& $(0.0242)$ & $(0.0006)$ & $(0.0004)$ & $(0.0041)$ & $(0.0017)$ & $(0.0125)$ \\
Outside & 0.0512 & 0.0009 & -0.0006 & 0.0035 & 0.0000 & -0.0192 \\
& $(0.0127)$ & $(0.0004)$ & $(0.0003)$ & $(0.0020)$ & $(0.0010)$ & $(0.0100)$ \\
Residence & 0.0391 & 0.0003 & -0.0003 & 0.0030 & 0.0003 & -0.0140 \\
& $(0.0179)$ & $(0.0004)$ & $(0.0003)$ & $(0.0014)$ & $(0.0011)$ & $(0.0092)$
\end{tabular}

Dependent variable: Log of Number of Violent Crimes

\begin{tabular}{|c|c|c|c|c|c|c|}
\hline & $\hat{C O}$ & $\mathrm{NO}_{2}$ & $\hat{O}_{3}$ & $P \hat{M}_{10}$ & $P \hat{M}_{25}$ & $S \hat{O}_{2}$ \\
\hline \multirow[t]{2}{*}{ Commercial } & 0.0527 & 0.0004 & -0.0004 & 0.0040 & -0.0005 & -0.0191 \\
\hline & $(0.0242)$ & $(0.0006)$ & (0.0004) & $(0.0041)$ & $(0.0017)$ & $(0.0125)$ \\
\hline \multirow[t]{2}{*}{ Outside } & 0.0512 & 0.0009 & -0.0006 & 0.0035 & 0.0000 & -0.0192 \\
\hline & $(0.0127)$ & $(0.0004)$ & (0.0003) & $(0.0020)$ & $(0.0010)$ & $(0.0100)$ \\
\hline Residence & $\begin{array}{c}0.0391 \\
(0.0179)\end{array}$ & $\begin{array}{c}0.0003 \\
(0.0004)\end{array}$ & $\begin{array}{l}-0.0003 \\
(0.0003)\end{array}$ & $\begin{array}{c}0.0030 \\
(0.0014)\end{array}$ & $\begin{array}{c}0.0003 \\
(0.0011)\end{array}$ & $\begin{array}{l}-0.0140 \\
(0.0092)\end{array}$ \\
\hline Std. Dev. & 0.44 & 14.3 & 23.2 & 25.1 & 12.5 & 6.9 \\
\hline
\end{tabular}

Notes: This table show the point estimates of an instrumental variable regression design on the number of each crime category happening in a two kilometer radius around the monitoring stations. The instrumental variable to capture the effect of pollution on crime is wind direction. The specification contains, year, month, weekday, and hour temporal fixed effects as well as station fixed effects and weather covariates. Standard errors are clustered at the station level.

\subsection{Lag Model}

It is possible that air pollution only shifts the timing of crimes across hours of the day. For example, a burglar who did not commit the burglary because high levels of exposure forced the family to stay home taking care of their child, would likely come back the next day or in a couple of hours to break in. To explore heterogeneous temporal effects, I run the preferred design plus twelve and twenty-four lags on the level of air pollution. In this section, I concentrate solely on violent offenses because this is the crime category with the most robust results. Equation 9 shows the second-stage regression of the IV design with the additional lags as covariates. 


$$
C_{c t}^{\text {Violent }}=\gamma_{i} \hat{P o l}_{c t}^{i}+\beta_{t-j} \sum_{j=1}^{T \in[12,24]} P o \hat{l}_{c t-j}^{i}+\gamma_{2} X_{c t}+\Omega_{t}+\lambda_{c}+\varepsilon_{c t}
$$

Image 5 shows the results of this specification for twelve lags. Most of the action happens on the contemporaneous effect, plus lags one, two, and three. Suggesting that the hourly level of air pollution only has short term consequences in criminal behavior. In this design, the only significant point estimates appear for $\mathrm{CO}, \mathrm{PM}_{25}$, and $\mathrm{O}_{3}$. For all three pollutants, there is evidence of a harvesting effect, where a decrease in lags one, two, and three balances the positive increment at time $t$.
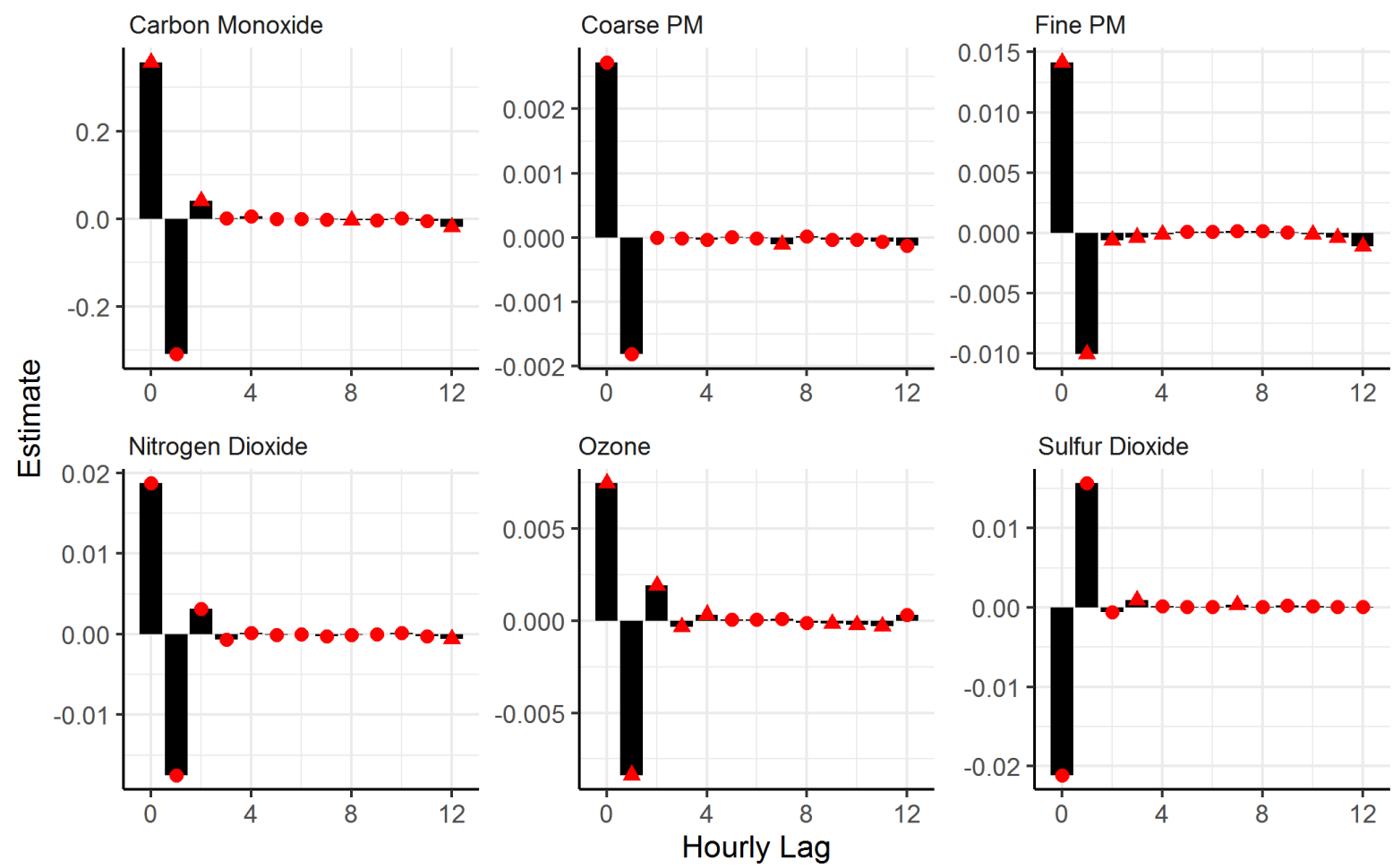

- Non Significant $\Delta$ Significant

Figure 5: Response of simulated crime data to variations in key variables

Notes: This grid shows the coefficients of the preferred IV specification for twelve lagged values of air pollution on violent crimes.

Next, I compute the total impact across twelve and twenty-four lags by linearly combining the point estimates of each lag. Table 8 shows the linear combination of point estimates for violent crimes across twelve and twenty-four lags. In the table, each offense has two coefficients coming from either combining only significant or all lagged point estimates. I interpret 
the value as the impact of increasing each particle by one unit on the cumulative crime rate twelve and twenty-four hours after the increment. For twelve hours, both, the linear combination of all lagged estimates and the linear combination of only significant lagged estimates show that increasing $\mathrm{CO}, \mathrm{NO}_{2}, \mathrm{O}_{3}, P M_{25}$, and $P M_{10}$ increase the number of crimes on the vicinity of monitoring stations. Increasing each particle by one standard deviation at time $t$, raises crimes by $2.79 \%, 3.99 \%, 1.88 \%, 2.35 \%$, and $1.25 \%$, respectively. The coefficients for only significant estimates decrease the impact of $C O, P M_{25}$, and $P M_{10}$ while increasing for the other contaminants. For the effect after twenty four hours, we see that increasing $\mathrm{CO}, \mathrm{NO}_{2}$, $O_{3}, P M_{25}$, and $P M_{10}$ by one standard deviation rises the number of violent crimes by $1.39 \%$, $1.23 \%, 2.00 \%, 3.01 \%$, and $1.25 \%$, respectively. These impacts are quite similar to the daily effects found by Herrnstadt et al. (2016) and Herrnstadt and Muehlegger (2015) regarding the effect of daily variations in ozone in Los Angeles and of particle matter in Chicago.

Table 8: Instrumental variable design on lagged variables

\begin{tabular}{|c|c|c|c|c|c|c|}
\hline & \multicolumn{6}{|c|}{ Linear combination of point estimates for twelve lags } \\
\hline & $\hat{C O}$ & $\mathrm{NO}_{2}$ & $\hat{O}_{3}$ & $P \hat{M}_{10}$ & $P \hat{M}_{25}$ & $S \hat{O}_{2}$ \\
\hline \multirow[t]{3}{*}{ Significant } & $\begin{array}{c}0.0008 \\
(0.0001) \\
0.0005 \\
(0.00000)\end{array}$ & $\begin{array}{c}0.0623 \\
(0.0046) \\
0.0814 \\
(0.0053)\end{array}$ & $\begin{array}{c}-0.0039 \\
(0.0004) \\
-0.0039 \\
(0.0004)\end{array}$ & $\begin{array}{c}0.0019 \\
(0.0001) \\
0.0004 \\
(0.0000)\end{array}$ & $\begin{array}{c}0.0028 \\
(0.0002) \\
0.0034 \\
(0.0003)\end{array}$ & $\begin{array}{c}0.0005 \\
(0.0001) \\
0.0005 \\
(0.0001)\end{array}$ \\
\hline & \multicolumn{6}{|c|}{ Linear combination of point estimates for twenty-four lags } \\
\hline & $\hat{C O}$ & $\mathrm{NO}_{2}$ & $\hat{O}_{3}$ & $P \hat{M}_{10}$ & $P \hat{M}_{25}$ & $S \hat{O}_{2}$ \\
\hline $\begin{array}{c}\text { All } \\
\text { Significant }\end{array}$ & $\begin{array}{c}0.0006 \\
(0.0001) \\
0.0003 \\
(0.0001)\end{array}$ & $\begin{array}{c}0.0276 \\
(0.0032) \\
0.0435 \\
(0.0037)\end{array}$ & $\begin{array}{c}-0.0034 \\
(0.0004) \\
-0.0034 \\
(0.0004)\end{array}$ & $\begin{array}{c}0.0016 \\
(0.0001) \\
0.0002 \\
(0.0002)\end{array}$ & $\begin{array}{c}0.0021 \\
(0.0002) \\
0.0024 \\
(0.0002)\end{array}$ & $\begin{array}{c}0.0005 \\
(0.0001) \\
0.0006 \\
(0.0001)\end{array}$ \\
\hline Std. Dev. & 0.44 & 14.3 & 23.2 & 25.1 & 12.5 & 6.9 \\
\hline
\end{tabular}

Notes: This table shows the linear combination of point estimates for twelve and twenty-four lags on the number of violent crimes happening in a two-kilometer radius around the monitoring stations. The instrumental variable to capture the effect of pollution on crime is wind direction. The specification contains, year, month, weekday, and hour temporal fixed effects as well as station fixed effects and weather covariates. Standard errors clustered at the station level.

\subsection{Non-Linearities}

The final section of the empirical study explores the effect of non-linearities in the doseresponse function of air pollution. Intuitively, the dose-response function can have different 
shapes; it can grow linearly with air pollution, decrease linearly, or exhibit non-linear effects. For instance, air pollution could steadily increase criminality until a certain morbidity threshold, where extreme levels of exposure could reduce the number of crime opportunities and criminals in the market.

Because of the large number of crimes and contaminants, in this last section, I only concentrate on the non-linear effects of $P M_{25}$. I focus on this pollutant for two reasons. First, dividing the causal variable into ten deciles increases the number of endogenous variables without changing the number of instruments. As such, I cannot run the IV design when I explore non-linearities. Fortunately, $P M_{25}$ shows the least variation between the OLS and IV models. Second, $P M_{25}$ is more challenging to avoid because its small size allows it to pass through walls and affect people indoors; this reduces the possibility of adaptations at high-levels of exposure.

To understand the dose-response function of $P M_{25}$, I subdivide the exposure level into ten deciles. Equation 10 shows the functional form behind these results. In it, $\sum_{d=1}^{D} \beta_{d} P o l_{c t}^{i d}$ represents the ten deciles in which I divide the causal variable. I run this equation for six different crime categories (aggravated assault, non-aggravated assault, robbery, burglary, larceny, and sexual offense) to infer different effects across felonies.

$$
C_{c t}=\sum_{d=1}^{D} \beta_{d} P o l_{c t}^{i d}+\gamma_{2} X_{c t}+\Omega_{t}+\lambda_{c}+\varepsilon_{c t}
$$

Figure 6 exhibits the point estimates of each decile concerning the lowest. First, the results for both types of assault look quite similar. For aggravated assaults, all deciles appear significantly higher than the lowest, while for non-aggravated assault, only the higher concentrations show significance. Concerning property crimes, the only violent property offense, robbery, has very similar behavior to assaults, with its dose-response function growing exponentially. Next, for burglary, the small sample size does not allow me to pin-point any significant difference between the first and the other deciles. However, it looks like that at very high concentrations (10th decile), the point estimate drops dramatically, suggesting a negative impact of pollution on the matching between criminals and crime opportunities. Another exciting result is the linear relationship between $P M_{25}$ and larcenies, implying that it is not just an increment in the test for violence driving the connection between pollution and crime. Finally, sexual crimes seem to increase linearly until the last deciles of the distribution, where their 
point estimates drop significantly. The highest decile, for instance, is not statistically different from a pristine day, suggesting that both the impact of pollution on impulsive behavior and on the tightness of the market play a role in the dose-response function of sexual offenses.

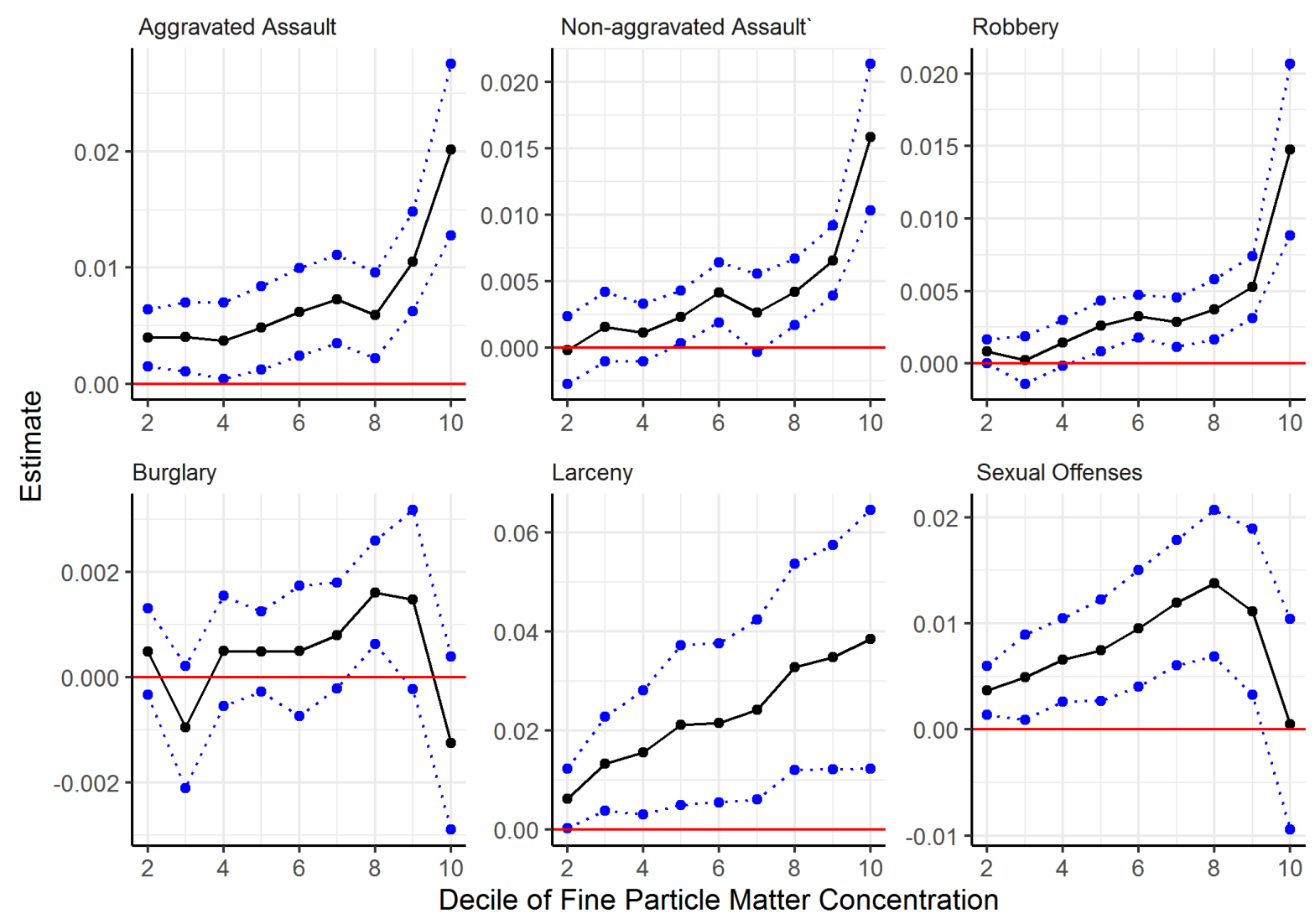

Figure 6: Non-linear behavior of $P M_{25}$

Notes: This grid shows the non-linear point estimates of $P M_{25}$ on the log of each crime category. The base decile is the lowest. Blue lines represent $90 \%$ confidence intervals. Standard errors clustered at the station level

\section{Mechanisms}

This section proposes mechanisms for the relationship between air pollution and criminality by combining the empirical results with the theoretical models of section 3 . It is important to take these mechanisms with a grain of salt, as without in-lab experiments, it is very challenging to disentangle the actual pathways through which pollution affects criminality, primarily because several of these pathways can co-occur and shadow each other. Still, I expect the following conjectures could shed some light on the relationship between both variables.

First, I find evidence that air pollution affects both the individual propensity to commit a crime and, for a subset of felonies, the matching between criminals and crime oppor- 
tunities. For the individual decision to commit a crime, the empirical estimates show that violent offenses tend to increase significantly more than non-violent ones, even after controlling for the premeditated nature and ultimate goal of the offense. As such, it appears that the criminal obtains an extra utility from violent behavior, transforming the reward from committing a violent felony from $\left(y_{c}-\beta F\right)$ to $\left(y_{c}+v\left(p o l^{i}\right)-\beta F\right)$, where $v\left(p o l^{i}\right)$ represents the extra utility from violence as a function of air pollution $\left(\mathrm{pol}^{i}\right)$. Thus, to explain the linear increase of violent crimes with exposure, I propose that the term $v\left(\mathrm{pol}^{i}\right)$ rises with air pollution: $\frac{\partial v\left(p o l^{i}\right)}{p o l^{i}}>0 \forall i \in\left[c o, p_{25}, O_{3}, n_{2}, p_{10}\right] \wedge \forall$ Crimes $\in$ Violent.

Further, even though the majority of positive coefficients pertain to violent crimes, there are still significant point estimates for larcenies, a non-violent unpremeditated offense. The results for larceny can occur through an effect of pollution on the probability of apprehension, the shape of the utility function, the shape of the prelec weighting function, or the discounting of future punishments. Concerning the probability of apprehension, I suggest that it is independent of hourly variations in air pollution because it is unlikely that hourly changes in pollution would affect external conditions sufficiently to spur changes in individual behavior. Additionally, the regression design on different crime premises finds significant coefficients for crimes happening inside houses, which are less likely to be affected by external conditions like visibility or the number of active police units. Regarding changes in the shape of the utility function to more risk-seeking forms, it is unlikely that air contaminants would increase the risk-seeking behavior of individuals, as previous evidence on the impact of pollution on risk-seeking attitudes show decreased risk behaviors on stock markets (Heyes et al., 2016) and national lotteries (Bondy et al. 2020). Respecting the discounting of future punishments, Bondy et al.(2020) put forward medical evidence on the likely relationship between air pollution and discounting: Li et al. (2017) show evidence that increased exposure to $P M_{25}$ can increase the level of stress hormones in the bloodstream and Riis-Vestergaard et al. (2018) demonstrate that stress hormones like cortisol, increase the time-preference for small and immediate rewards versus larger but delayed benefits. Finally, if it is the Prelec weighting function, this would mean that larceners put different weights on the probability of getting caught when exposed to air pollution, probably by subconsciously increasing their chances of success. Remember that the Prelec weighting function takes the form $w_{i}(p)=\exp \left\{-B_{i}\left[-\ln \left(p_{i}\right)\right]_{i}^{\alpha}\right\}$; thus, this conjecture implies that as air pollution increases, either B or $\alpha$ decrease: $\alpha_{\Pi^{i}} \leq 0 \wedge B_{\Pi^{i}} \leq 0 \forall i \in c($ co,no 2$) \wedge \forall$ crimes $\in$ Larceny. Unfortunately, I cannot disentangle the impact of air pollution on the discounting of 
future punishments from its impact on the functional form of the prelec weighting function.

Finally, pertaining to the effect of air pollution in the matching between criminals and crime opportunities. I find that, for burglary, the number of offenses decreases with air pollution. This effect is in concordance with the theoretical model on search and matching frictions of section 3 , where a reduction in the number of crime opportunities decreases the number of matches between opportunities and criminals. Intuitively, the number of empty houses available to burglars decreases because pollution increases morbidity episodes, forcing people to stay indoors, and thus reducing the pool of empty houses a typical burglar would prefer to rob.

\section{8. conclusion}

This article looks at the effect that hourly variations in air pollution have on criminality. I develop two theoretical models to motivate the empirical analysis and understand the connection between both variables, one model of the individual decision to commit a crime with behavioral prospect theory, and a search and matching frictions model between criminals and crime opportunities. The models allow me to propose mechanisms through which air pollution could affect criminality. This is the first study to examine the impact of hourly variations in pollution on criminal behavior. The first to use behavioral prospect theory to analyze the theoretical effect of pollution on the individual decision to commit a crime. The first to use a search and matching frictions models to explore the effect of air pollution on the matching between individuals and crime opportunities, and the first showing that the relationship between pollution and criminality does not just depend on the personal consequences of exposure, but also on the conditions of the market for criminal activities.

The data consists of criminal records and hourly air pollution compilations for the four largest urban agglomerations in North America; Mexico City, Los Angeles, Toronto, and New York City. I merge pollution and criminal data by drawing a two-kilometer radius around each monitoring station and counting the number of criminal offenses within that range. Moreover, I subclassify crimes into twelve groups of crimes to understand heterogeneous effects across different crime typologies.

I infer the causal relationship between both variables with panel and instrumental variable models that exploit the high degree of temporal and spatial variation across and within monitoring stations. The preferred econometric specification uses wind direction as an instru- 
ment while controlling for weather covariates and a battery of temporal and spatial fixed effects like hour, weekday, month, year, and station fixed effects.

The main results show that, on average, $\mathrm{O}_{3}, \mathrm{NO}_{2}$, and $\mathrm{PM}_{25}$ increase the number of crimes happening in the vicinity of monitoring stations. Increasing their hourly level by one standard deviation increases the number of hourly felonies by $11.37 \%, 5.57 \%$, and $6.79 \%$, respectively. Moreover, I find that violent and unpremeditated felonies massively drive this effect. Specifically, for violent crimes, I find positive and significant point estimates for $C O$, $N O_{2}, P M_{25}, P M_{10}$, and $O_{3}$. To disentangle if the impact comes from the violent nature of the felonies and not from the unpremeditated characteristics of violent crimes, I compare two commonly unpremeditated violations, aggravated and non-aggravated assaults as well as two unpremeditated property crimes, robbery and larceny. These crime groups only vary in their level of exercised violence while remaining quite similar in the ultimate goal of the felony. The point estimates of this exercise are higher for aggravated assault and robbery, showing that an increase in the taste for violence drives part of the coefficients. However, this does not mean that only violence drives the effect, as I also find significance for unpremeditated nonviolent offenses like larceny. Additionally, I show that not all crime categories increase with air pollution. For crimes that rely on the availability of crime opportunities, the effect of pollution can go in the other direction. For example, I find that burglaries decrease when air pollution rises. These last results show an outcome previously disregarded in the literature regarding the relationship between crime and anthropogenic emissions, their effect on the matching between crime opportunities and criminals.

In further results, I use information on crime premises to argue that it is unlikely that crimes increase because of a change in the probability of apprehension. I do this by claiming that the only way air pollution can affect the arrest probability is either through reduced visibility or through health-related reductions to the police force. If this is the case, it is unlikely that we would find impacts on crimes happening inside residences. However, I do see an effect across premises, suggesting that it is not a change in the probability of arrest driving the point estimates. Furthermore, I analyze the inter-temporal effects of exposure. The results from this exercise suggest that increments occurring at time $t$ are partially compensated at times $t+1$, and $t+2$. However, even despite this compensation, the cumulative effect twelve and twentyfour hours after variations in an exposure remains. Finally, I study non-linear effects for $P M_{25}$, where I provide evidence for a linear relationship with violent offenses like assault and robbery, 
a linear relationship also with non-violent unpremeditated crimes like larceny, and an inverted u-shape relation for two crime categories: sexual crimes, and burglary.

The empirical results further allow me to theoretize on the pathways through which air pollution affects criminality. First, for certain crimes like burglary, air pollution decreases the number of felonies by changing the ratio between criminals and crime opportunities. For example, air pollution forces people to stay home through morbidity, reducing the number of empty homes to rob. Second, for those crimes that experience an increase with air pollution, it is clear that a rise in the reward for violence drives a significant part of the increment, this is obvious when we compare the level of significance and the size of the point estimates between violent and non-violent crimes. However, this is not the only reason behind the increase, as we can also see effects on non-violent offenses like larceny. I hypothesize that for these nonviolent unpremeditated crimes, it is either an increase in the eagerness for rewards or a change in the individual weighting of real word probabilities behind the significant coefficients.

The results of this article show that the relationship between pollution and crime is not straightforward. Although some criminal behaviors increase with air pollution, others tend to decrease. The impact depends on the nature of the crime and the matching of criminals with crime opportunities. Police departments can use these results to shift resources in times of exacerbated air pollution across crime categories, by policymakers to include the hourly increment in criminal offenses on cost-benefit analyses of environmental policies aiming to the correct implementation of Pigouvian taxes, cap-and-trade mechanisms, or command and control policies, and by epidemiologist as empirical evidence on the impact of air pollution on the brain. Finally, The results also confirm the findings of Burkhardt et al. (2019); Bondy et al. (2020); Herrnstadt et al. (2016), and Herrnstadt and Muehlegger (2015) regarding the daily effects of air pollution on criminality, and call for a more profound understanding of the physiological mechanisms triggering the increment on the individual propensity to commit a crime.

\section{References}

Aire (2020) Direccion de Monitoreo Atmosferico de la Ciudad de Mexico. Data retrieved from, http://www.aire.cdmx.gob.mx/default.php.

Anderson C. A. and Bushman B. J. (2002) Human aggression. Annual review of psychology, 
Aragon F., Miranda J. J., Oliva P. et al. (2016) Particulate matter and labor supply: evidence from Peru. Simon Fraser University Economics Working Paper. Google Scholar.

Barwick P. J., Li S., Rao D., and Zahur N. B. (2018) The Morbidity Cost of Air Pollution: Evidence from Consumer Spending in China. NBER Working Paper No. 24688.

Becker G. S. (1968) Crime and punishment: An economic approach. in The economic dimensions of crime: Springer: 13-68.

Beurel E. and Jope R. S. (2014) Inflammation and lithium: clues to mechanisms contributing to suicide-linked traits. Translational psychiatry, 4(12): e488-e488.

Block M. L. and Calderón-Garcidueñas L. (2009) Air pollution: mechanisms of neuroinflammation and CNS disease. Trends in neurosciences, 32(9): 506-516.

Bondy M., Roth S., and Sager L. (2020) Crime is in the Air: The Contemporaneous Relationship between Air Pollution and Crime. Journal of the Association of Environmental and Resource Economists, 7(3): 555-585.

Briere J., Downes A., and Spensley J. (1983) Summer in the city: urban weather conditions and psychiatric emergency-room visits.. Journal of Abnormal Psychology, 92(1): 77.

Burkhardt J., Bayham J., Wilson A., Carter E., Berman J. D., O’Dell K., Ford B., Fischer E. V., and Pierce J. R. (2019) The effect of pollution on crime: Evidence from data on particulate matter and ozone. Journal of Environmental Economics and Management, 98: 102267.

CDMX (2020) Portal de datos de la Ciudad de Mexico. Data retrieved from, https://datos . cdmx.gob.mx/pages/home/.

Chang T. Y., Graff Zivin J., Gross T., and Neidell M. (2019) The effect of pollution on worker productivity: evidence from call center workers in China. American Economic Journal: Applied Economics, 11(1): 151-72.

Chen C.-Y., Bonham A. C., Plopper C. G., and Joad J. P. (2003) Selected Contribution: Neuroplasticity in nucleus tractus solitarius neurons after episodic ozone exposure in infant primates. Journal of Applied Physiology, 94(2): 819-827. 
Chen S., Guo C., and Huang X. (2018) Air Pollution, Student Health, and School Absences: Evidence from China. Journal of Environmental Economics and Management, 92: 465-497.

Crockett M. J., Apergis-Schoute A., Herrmann B., Lieberman M. D., Müller U., Robbins T. W., and Clark L. (2013) Serotonin modulates striatal responses to fairness and retaliation in humans. Journal of neuroscience, 33(8): 3505-3513.

Currie J., Hanushek E. A., Kahn E. M., Neidell M., and Rivkin S. G. (2009) Does pollution increase school absences? The Review of Economics and Statistics, 91(4): 682-694.

EPA (2020) Environmental Protection Agency. Data retrieved from, https://aqs .epa.gov/ aqsweb/airdata/download_files.html\#Raw.

Gilliland F. D., Berhane K., Rappaport E. B., Thomas D. C., Avol E., Gauderman W. J., London S. J., Margolis H. G., McConnell R., Islam K. T. et al. (2001) The effects of ambient air pollution on school absenteeism due to respiratory illnesses. Epidemiology: 43-54.

Hanna R. and Oliva P. (2015) The effect of pollution on labor supply: Evidence from a natural experiment in Mexico City. Journal of Public Economics, 122: 68-79.

Herrnstadt E., Heyes A., Muehlegger E., and Saberian S. (2016) Air pollution as a cause of violent crime: Evidence from Los Angeles and Chicago. Manuscript in preparation.

Herrnstadt E. and Muehlegger E. (2015) Air pollution and criminal activity: Evidence from chicago microdata.Technical report, National Bureau of economic research.

Heyes A., Neidell M., and Saberian S. (2016) The effect of air pollution on investor behavior: Evidence from the S\&P 500.Technical report, National Bureau of Economic Research.

Iskandar A., Andersen Z. J., Bønnelykke K., Ellermann T., Andersen K. K., and Bisgaard H. (2012) Coarse and fine particles but not ultrafine particles in urban air trigger hospital admission for asthma in children. Thorax, 67(3): 252-257.

Jayachandran S. (2009) Air quality and early-life mortality evidence from Indonesia's wildfires. Journal of Human Resources, 44(4): 916-954.

Kahneman D. and Tversky A. (1979) Prospect Theory: An Analysis of Decision Under Risk, Econometrica, vol. 47, pp 263-291. 
Kaldor N. (1939) Welfare propositions of economics and interpersonal comparisons of utility. The Economic Journal: 549-552.

Knittel C. R., Miller D. L., and Sanders N. J. (2016) Caution, Drivers! Children Present: Traffic, Pollution, and Infant Health. Review of Economics and Statistics, 98(2): 350-366.

LA (2020) Los Angeles Open Data Portal. Data retrieved from, https://data. lacity.org/.

Li H., Cai J., Chen R., Zhao Z., Ying Z., Wang L., Chen J., Hao K., Kinney P. L., Chen H. et al. (2017) Particulate matter exposure and stress hormone levels: a randomized, double-blind, crossover trial of air purification. Circulation, 136(7): 618-627.

Moretti E. and Neidell M. (2011) Pollution, health, and avoidance behavior evidence from the ports of Los Angeles. Journal of Human Resources, 46(1): 154-175.

Mortensen D. T. and Pissarides C. A. (1994) Job creation and job destruction in the theory of unemployment. The review of economic studies, 61(3): 397-415.

Murphy S. R., Schelegle E. S., Miller L. A., Hyde D. M., and Van Winkle L. S. (2013) Ozone exposure alters serotonin and serotonin receptor expression in the developing lung. toxicological sciences, 134(1): 168-179.

NAPS (2020) National Air Pollution Suerveilance. Data retrieved from, https://open. canada.ca/data/en/dataset/1b36a356-defd-4813-acea-47bc3abd859b

NYC (2020) New York City Open Data Portal. Data retrieved from, https://opendata. cityofnewyork.us/1.

Olsen R. A. (1997) Prospect theory as an explanation of risky choice by professional investors: Some evidence. Review of Financial Economics, 6(2): 225-232.

Pareto V. and Cours D. (1896) Economic politique. Lausanne, Switzerland, Rouge.

Petruzzi S., Fiore M., Dell'Omo G., and Alleva E. (1995) Exposure to ozone inhibits isolationinduced aggressive behavior of adult CD-1 male mice. Aggressive Behavior, 21(5): 387396.

Prelec D. et al. (1998) The probability weighting function. Econometrica-Evanston Illinois, 66: 497-528. 
Riis-Vestergaard M. I., van Ast V., Cornelisse S., Joëls M., and Haushofer J. (2018) The effect of hydrocortisone administration on intertemporal choice. Psychoneuroendocrinology, 88: $173-182$.

Rotton J. and Frey J. (1985) Air pollution, weather, and violent crimes: Concomitant timeseries analysis of archival data.. Journal of personality and social psychology, 49(5): 1207.

Soulage C., Perrin D., Cottet-Emard J.-M., Pequignot J., Dalmaz Y., and Pequignot J.-M. (2004) Central and peripheral changes in catecholamine biosynthesis and turnover in rats after a short period of ozone exposure. Neurochemistry international, 45(7): 979-986.

Tolbert P. E., Mulholland J. A., Macintosh D. L., Xu F., Daniels D., Devine O. J., Carlin B. P., Klein M., Butler A. J., Nordenberg D. F. et al. (2000) Air quality and pediatric emergency room visits for asthma and Atlanta, Georgia. American Journal of Epidemiology, 151(8): 798-810.

TPS (2020) Toronto Public Safety Data Portal. Data retrieved from, http://data. torontopolice.on.ca/pages/maps

Tversky A. and Kahneman D. (1992) Advances in prospect theory: Cumulative representation of uncertainty. Journal of Risk and uncertainty, 5(4): 297-323.

Yang A. C., Tsai S.-J., and Huang N. E. (2011) Decomposing the association of completed suicide with air pollution, weather, and unemployment data at different time scales. Journal of affective disorders, 129(1-3): 275-281.

Zivin J. G. and Neidell M. (2009) Days of haze: Environmental information disclosure and intertemporal avoidance behavior. Journal of Environmental Economics and Management, 58(2): 119-128.

(2012) The impact of pollution on worker productivity. The American Economic Review, 102(7): 3652-3673. 


\section{A. Tests on the Instrumental Variable}

Table 9: OLS regressions for each contaminant

\begin{tabular}{lccccc}
\hline \multirow{2}{*}{} & \multicolumn{5}{c}{ Results from first stage with wind direction as instrument } \\
\cline { 2 - 6 } & $\mathrm{co}$ & $\mathrm{no} 2$ & $\mathrm{o} 3$ & $\mathrm{pm} 25$ & $\mathrm{~s} 2$ \\
\hline Los Angeles & -0.0071 & -0.3508 & 0.3583 & -0.1368 & -0.0051 \\
& $(0.0001)$ & $(0.0021)$ & $(0.0023)$ & $(0.0034)$ & $(0.0002)$ \\
Mexico City & -0.0003 & -0.0061 & -0.0084 & -0.0106 & 0.0022 \\
& $(0.0000)$ & $(0.0001)$ & $(0.0002)$ & $(0.0002)$ & $(0.0001)$ \\
New York City & -0.0030 & -0.1778 & 0.2063 & -0.0660 & -0.0053 \\
& $(0.0000)$ & $(0.0018)$ & $(0.0016)$ & $(0.0005)$ & $(0.0007)$ \\
Toronto & 0.0007 & -0.0139 & -0.0966 & -0.0168 & -0.0031 \\
& $(0.0001)$ & $(0.0023)$ & $(0.0027)$ & $(0.0015)$ & $(0.0004)$ \\
\hline R-squared & 0.3470 & 0.4695 & 0.6239 & 0.1485 & 0.1819 \\
\hline
\end{tabular}

Notes: This table shows the results of the first stage regression of of air pollution as function of wind direction for each of the cities in the study. The specification contains, year, month, weekday, and hour temporal fixed effects, station fixed effects, and weather covariates.

\section{B. Classification of crimes and premises}

Table 10: Definitions of each crime category

\begin{tabular}{|c|c|}
\hline Classification & Definition \\
\hline Homicide & The crime of killing a person. \\
\hline Manslaughter & $\begin{array}{l}\text { The crime of killing a person when the killer did not intend to do it or cannot be } \\
\text { responsible for his or her actions. }\end{array}$ \\
\hline Aggravated assault & An unlawful attack where the victim suffers severe or aggravated injuries. \\
\hline Non-aggravated assault & $\begin{array}{l}\text { An unlawful attack where the criminal threatens the victim with the possibility of } \\
\text { suffering an aggravated assault. }\end{array}$ \\
\hline Burglary & The crime of illegally entering a building and stealing things. \\
\hline Robbery & $\begin{array}{l}\text { The crime of taking or attempting to take anything of value by force, threat of force, } \\
\text { or by putting the victim in fear. }\end{array}$ \\
\hline Larceny & $\begin{array}{l}\text { The crime of taking something that does not belong to you, without illegally entering } \\
\text { a building to do so. }\end{array}$ \\
\hline Rape & $\begin{array}{l}\text { To force someone to have sex when they are unwilling, using violence or threatening } \\
\text { behavior. }\end{array}$ \\
\hline Sex Crime & $\begin{array}{l}\text { All sex related crimes like pimping, lewd conduct, or sexual battery with the exception } \\
\text { of rape. }\end{array}$ \\
\hline Liberty Crimes & The act of unlawfully restraining somebody's liberty. \\
\hline Fraud & Include crimes as theft of identity, document forgery, or defrauding innkeeper. \\
\hline Other & All of the other crimes that are not contained in the previous classifications. \\
\hline
\end{tabular}

Notes: This table contains the definition of each crime category in the paper 
Table 11: Crime classification for Los Angeles

\begin{tabular}{|c|c|}
\hline Classification & Crimes \\
\hline Homicide & Homicide \\
\hline Manslaughter & Manslaughter \\
\hline Aggravated Assault & $\begin{array}{l}\text { Assault with deadly weapon, battery, assault with deadly weapon on police officer, } \\
\text { physical child abuse (aggravated assault), intimate partner (aggravated assault), shots } \\
\text { fired at vehicle, shots fired at inhabited dwelling, train wrecking. }\end{array}$ \\
\hline Non aggravated Assault & $\begin{array}{l}\text { Other assault, intimate partner (simple assault), child abuse physical (simple assault), } \\
\text { threatening }\end{array}$ \\
\hline Burglary & Burglary, attempted burglary, burglary from vehicle, attempted burglary from vehicle \\
\hline Robbery & Robbery \\
\hline Larceny & $\begin{array}{l}\text { Theft from motor vehicle, grand theft, shoplifting, dishonest employee, insurance } \\
\text { fraud, auto repair, person theft, purse snatching,pickpocket, plain theft, till tap, theft } \\
\text { of coin machine, stolen bike, stolen boat, stolen vehicle }\end{array}$ \\
\hline Rape & Rape, Sexual penetration with foreign object, oral copulation, sodomy \\
\hline Sex Crime & $\begin{array}{l}\text { Lewd, stalking, pimping, pandering, unlawful sex, sexual crimes against children, } \\
\text { child annoying, child pornography, human trafficking for sexual acts, bestiality, inde- } \\
\text { cent exposure, battery with sexual contact, peeping tom, letters and lewd. }\end{array}$ \\
\hline Liberty Crimes & Kidnapping, human trafficking, child stealing \\
\hline Fraud & $\begin{array}{l}\text { Theft of identity, document forgery, document worthless, credit cards fraud use, coun- } \\
\text { terfeit, bunco, embezzlement, extortion, bribery, conspiracy, defrauding innkeeper }\end{array}$ \\
\hline Homicide & Homicide \\
\hline Other & $\begin{array}{l}\text { Child neglect, drunk roll, blocking door induction center, driving without owner con- } \\
\text { sent, false imprisonment,lynching, resisting arrest, reckless driving, false police re- } \\
\text { port, arson, unauthorized computer access, vandalism, discharge firearms, bomb scare, } \\
\text { weapons possession, brandish weapon, drugs to a minor, child abandonment, disrupt } \\
\text { school, inciting riot, failure to disperse, disturbing the peace, trespassing, failure to } \\
\text { yield, violation of court order, violation o restraining order, contempt of court, dam- } \\
\text { age to telephone property, replica firearms, prowler, cruelty to animals, other crimes, } \\
\text { bigamy, illegal dumping, abortion, , contributing }\end{array}$ \\
\hline
\end{tabular}

Notes: This table contains the relationship between the crime categories used in the paper and the categories reported by Los Angeles Police Department

Table 12: Crime classification for Toronto

\begin{tabular}{|c|l|}
\hline Classification & \multicolumn{1}{c|}{ Crimes } \\
\hline Aggravated Assault & $\begin{array}{l}\text { Aggravated assault, shooting, stabbing, unlawfully causing bodily harm, use firearm } \\
\text { to commit an offence, place trap intending death }\end{array}$ \\
\hline Non-aggravated Assault & Assault, pointing a firearm \\
\hline Burglary & Breaking and Entering, Unlawfully in dwelling-house \\
\hline Robbery & Robbery \\
\hline Larceny & Theft \\
\hline Other & $\begin{array}{l}\text { Administering noxious thing, negligence and bodily harm, disarming peace, discharge } \\
\text { fire arm - recklessly, other, pointing a firearm, place trap and intent death, traps likely } \\
\text { to cause bodily harm }\end{array}$ \\
\hline
\end{tabular}

Notes: This table contains the relationship between the crime categories used in the paper and the categories reported by Toronto Police Department 
Table 13: Crime classification for New York City

\begin{tabular}{|c|c|}
\hline Classification & Crimes \\
\hline Homicide & Homicide \\
\hline Manslaughter & Homicide negligent \\
\hline Aggravated Assault & Assault, strangulation, obstruct breathing. \\
\hline Non-aggravated Assault & Menacing, coercion, mischief, tampering \\
\hline Burglary & Trespass, burglars tools, burglary, unlawful possession fo radio devices \\
\hline Robbery & Robbery \\
\hline Larceny & Petit larceny, grand larceny, theft, stolen property, stolen motor vehicle, dog stealing \\
\hline Rape & Rape, sodomy \\
\hline Sex Crime & $\begin{array}{l}\text { Sexual misconduct, sexual abuse, sex crimes, sexual offense, aggravated sexual injury, } \\
\text { luring a child, solicitation, facilitation, prostitution, sex trafficking, obscenity, harass- } \\
\text { ment, bigamy, incest, promoting a sexual performance, use of a child in a sexual per, } \\
\text { incest }\end{array}$ \\
\hline Liberty Crimes & Kidnapping, labor trafficking, custodial interference \\
\hline Fraud & $\begin{array}{l}\text { conspiracy, accosting, Fortune telling, credit card fraud, theft of services, bribery, bad } \\
\text { check, forgery, false records, impersonation, fraud, manufacture unauthorized record- } \\
\text { ing, sale of unauthorized records, enterprise corruption, usury, money laundering, tax } \\
\text { law }\end{array}$ \\
\hline Other & $\begin{array}{l}\text { End welfare elderly, reckless endangerment, promoting suicide, abortion, unlawful } \\
\text { imprisonment, criminal contempt, arson, posting advertisements, unauthorized use } \\
\text { vehicle, jostling, controlled substances, drug paraphernalia, gambling, unlawful pos- } \\
\text { session of a weapon, loitering, disorderly conduct, exposure, healthcare offenses, un- } \\
\text { lawful assembly, false reports, riot, nuisance, lewdness, terrorism, privacy offenses, } \\
\text { eavesdropping, endangering, tampering with a witness, escape, bail jumping, perjury, } \\
\text { resist arrest, absconding from work release, computer crimes, weapons possession, } \\
\text { fireworks, navigation law, public health law, marriage offenses, environmental control } \\
\text { board, traffic offenses, leaving a scene of accident, unlawful parking, health code vio- } \\
\text { lation, gratuity, administrative code violation, unlicensed taxi, noise, air pollution, NY } \\
\text { state laws, unclassified violation. }\end{array}$ \\
\hline
\end{tabular}

Notes: This table contains the relationship between the crime categories used in the paper and the categories reported by New York City Police Department 
Table 14: Crime classification for Mexico City

\begin{tabular}{|c|c|}
\hline Classification & Crimes \\
\hline Homicide & Homicide, Femicide \\
\hline Manslaughter & Negligent homicide \\
\hline Aggravated Assault & Intentional Injuries \\
\hline Non-Aggravated Assault & damage to property of others, intimidation, insults, extortion \\
\hline Burglary & Home burglary, breaking and entering \\
\hline Robbery & Violent Robbery \\
\hline Larceny & Robbery without violence \\
\hline Rape & Rape \\
\hline Sex Crime & $\begin{array}{l}\text { Sexual abuse, sexual harassment, corruption of minors, corruption of disabled, sexual } \\
\text { relationships with minor, exhibition of minors, pimping, child pornography }\end{array}$ \\
\hline Liberty Crimes & $\begin{array}{l}\text { Forced disappearance, unlawful delivery of a minor, kidnapping, deprivation of per- } \\
\text { sonal freedom, theft of infant, express kidnapping, child abduction, infant trafficking, } \\
\text { human trafficking }\end{array}$ \\
\hline Fraud & $\begin{array}{l}\text { Authority abuse, coaching of public servers, illegitimate collection, bribery, concus- } \\
\text { sion, crimes of patron, lawyers, and litigants, electoral crimes, defamation, abusive ex- } \\
\text { ercise of functions, improper exercise of public server, concealment, illicit enrichment, } \\
\text { false statement, forgery, falsification, fraud, denial of public service, operations with } \\
\text { resources of illicit provenance, peculation, break seals, use of false document, misuse } \\
\text { of attributions and powers, function usurpation, identity theft, profession usurpation }\end{array}$ \\
\hline Other & $\begin{array}{l}\text { Abandonment of person, abortion, trust abuse, delicious association, attack on com- } \\
\text { munication ways, assault on public peace, bigamy, land-use-change, pollution or } \\
\text { waste, crimes against the civil state, crimes against public officials, crimes against } \\
\text { the general law of explosives, guilty of property damage, damage to foreign property, } \\
\text { soil damage, human rights violations, environmental crimes, crimes against health, } \\
\text { disrespect, disobedience, disposition, discrimination, firearms, prisoner evasion ex- } \\
\text { hort, inhumations or exhumations, food insolvency, negligent injuries, animal abuse, } \\
\text { riot, drug dealing, opposition to public work, loss of life due to external factors, pro- } \\
\text { hibited weapons, assisted procreation, provocation of crime, resist arrest, professional } \\
\text { liability, reveal secrets, sabotage, illegal wood chopping, suicide attempt, torture, im- } \\
\text { proper use of the public road, correspondence violation, violation of privacy, family } \\
\text { violence. }\end{array}$ \\
\hline
\end{tabular}

Notes: This table contains the relationship between the crime categories used in the paper and the categories reported by the ministry of justice of Mexico City

Table 15: Classification of Premises

\begin{tabular}{|c|l|}
\hline Classification & \multicolumn{1}{|c|}{ Premise } \\
\hline & $\begin{array}{l}\text { Candy store, chain store, clothing boutique, department store, drug store, dry cleaner, } \\
\text { laundry, food supermarket, gas station, grocery, jewelry, liquor store, photo copy, shoe } \\
\text { store, telecommunications store, variety store, video store, store unclassified, small } \\
\text { merchant, restaurant, bar, church, gym, mosque, synagogue, fast food, social club, } \\
\text { beauty salon, loan company, doctor office, check cashing business, storage facility, } \\
\text { school, hospital, bank }\end{array}$ \\
\hline Residence & apartment house, house, public housing \\
\hline Outside & $\begin{array}{l}\text { Airport terminal, bridge, bus, bus stop, ferry, taxi, tramway, transit, street, parking lot, } \\
\text { park, highway, open areas, cemetery, tunnel, abandoned building }\end{array}$ \\
\hline
\end{tabular}

Notes: This table contains the the classification of premises for Los Angeles, New York City, and Toronto. 
Table 16: correlation matrix of all contaminants in the sample

\begin{tabular}{lrrrrrr}
\hline & $\mathrm{O}_{3}$ & $\mathrm{CO}$ & $\mathrm{SO}_{2}$ & $\mathrm{PM}_{25}$ & $\mathrm{NO}_{2}$ & $\mathrm{PM}_{10}$ \\
\hline $\mathrm{O}_{3}$ & 1.00 & -0.27 & -0.10 & 0.20 & -0.29 & 0.17 \\
$\mathrm{CO}$ & -0.27 & 1.00 & 0.19 & 0.49 & 0.73 & 0.55 \\
$\mathrm{SO}_{2}$ & -0.10 & 0.19 & 1.00 & 0.30 & 0.25 & 0.32 \\
$\mathrm{PM}_{25}$ & 0.20 & 0.49 & 0.30 & 1.00 & 0.54 & 0.86 \\
$\mathrm{NO}_{2}$ & -0.29 & 0.73 & 0.25 & 0.54 & 1.00 & 0.59 \\
$\mathrm{PM}_{10}$ & 0.17 & 0.55 & 0.32 & 0.86 & 0.59 & 1.00 \\
\hline
\end{tabular}

